\title{
Analysis of lean manufacturing strategy using system dynamics modelling of a business model
}

\section{Abstract}

Purpose - A system dynamics-based methodology is described for analysing the impact of lean manufacturing strategies on a company's business performance, using Business Model Canvas perspective.

Design/methodology/approach - A case study approach is used to describe the methodology which consists of conceptualizing a system dynamics model on the basis of Business Model Canvas. The base system dynamics model is elaborated to include variables and concepts that consider the effects of lean manufacturing metrics on business performance. In the modeling experimentation, the lean manufacturing metrics are made to take on likely values one would expect if certain lean practices are initiated or improved. The experimental results provide one with the likely impact on business performance, if one were to improve lean manufacturing practices.

Findings - The simulation results for the case study show that lean improvements, on the short-run, have a significant impact on business performance, but on the long-run, the impact is only marginal.

Research implications/limitations -The described methodology provides one with a structured format for investigating the impact of lean practices on business performance. Although the developed system dynamics model was built with generality in mind, it remains to be reproduced in other settings to test its replicability

Practical implications - The methodology enables an organization target which lean improvements to initiate based on their strategic impact on the business.

Originality/value - Limited studies exist where system dynamics and business models are combined to test the strategic impact of lean manufacturing.

Keywords - System dynamics; Business model; Lean manufacturing Paper type Research paper

\section{Introduction}

The concept of business model is still in the early stages of development. Although there is no agreement on a definition, business models have recently become a new level and unit of analysis for organization and strategy research (Zott et al. 2011). The study of the dynamics of business model evolution has a great promise to enhance the understanding of how organisations create and capture wealth (Zott and Amit, 2013). Modelling software tools are able to estimate and analyse about possible outcomes of complex systems. Especially, System Dynamics (SD) is a computer simulation modelling tool that excels at capturing cause and effect relationships, delays, non-linear effects 
and feedback effects of complex systems in a specified period of time. Sterman (2000) discussed that SD modelling can be applied for studying business scenarios. Applied to the business context, SD modelling can organize the descriptive information, build on the managers' knowledge from experience, and reveal the variety of dynamic behaviours that stem from different choices of strategies (Forrester, 2007a). Unlike spreadsheet or discrete event simulation methods, SD is grounded in subjective thinking with regard to the understanding of the "physics" (dynamic behaviour) of the components of the system.

The consequences of strategic initiatives inherently change one or more of the core characteristics of businesses and, thus, are time and cost intensive. Nevertheless, long term strategic decisions are driven by qualitative analyses based on experience and intuition, which frequently fail to predict the real consequences of these for organisations (Groesser and Jovy, 2015). Business models on their own are unable to quantify the benefits of strategic initiatives or operational improvements. Meanwhile, one may need to define additional operational activities when using standardized business models such as the European Foundation for Quality Management or Shingo Prize models, if one wanted to analyse detailed operational aspects (Duarte and Cruz-Machado, 2013), such as lean manufacturing practices. Business models on their own are also weak in capturing the evolution of a system, since they are typically used to depict a snapshot of specific time frames. This study considers business models as interdependent activity systems, which describe how firms create and capture value for customers. Then, system dynamics can potentially assess business strategies providing insights about the type and magnitude quantitative evaluation - of their consequences for business models, as a new unit of analysis. From a review of the current literature, there has been very little investigation in this field, which motivates the present work. This research uses a case-study approach to demonstrate how system dynamics can be used for analysing the impact of operational-level lean strategies on a firm's business model. In the current context, reference to lean strategies is taken to mean a combination of lean policies. Lean policies are the decisions to improve lean metrics, for example reducing production defect rate by say $10 \%$ per year by improving lean practices. The improvements in lean metrics and lean practices make up lean improvements. Lean practices encompass work habits and management practices aimed at eliminating waste and enhancing continuous improvement, and by so doing improve lean metrics. A case study print packaging manufacturer is used to demonstrate the proposed methodology. 
The main purpose of the current research is to assess the impact of lean manufacturing strategies prior to implementing them, taking into consideration the business model of the organization. A system dynamics model, consisting of sub-models to represent various aspects of the business, is built on the basis of the company's Business Model Canvas (BMC). A Business Model Canvas is considered because of its ability to capture, in a holistic way, the key elements that describe the business and its value chain. It is able to concisely depict what is happening in the business, which can then be formalised using a SD model. The BMC like other business models may need to be elaborated to include additional variables and concepts. In the current study, the base SD model from the $\mathrm{BMC}$ is therefore elaborated to include variables and concepts that consider the effects of lean manufacturing metrics on business performance metrics. In the experiments using the SD model, the lean manufacturing metrics are made to take on likely values one would expect if certain lean practices are initiated or improved. The experimental results provide one with a guide to the type of lean practices improvements that one should be looking at. In order to present the entire work, the remainder of the article is structured as follows: section two lays out a review of the literature on system dynamics and business modelling as well as how the impact of lean manufacturing is often assessed, section three is concerned with the methodology used to construct the SD model, section four presents the case company, indicates step-by-step the application of the modelling method to the case study and describes the specific SD model validation and simulation results. Section 5 discusses the insights derived from both the application of the modelling method and the results of the simulations. Lastly, section 6 concludes by summarising the findings of the study and introduces guidelines for future research. It is believed that the present research contributes to the knowledge by proposing a structured methodology for building SD firm-level models. Besides, this study serves as an empirical example of a real business applying system dynamics as a lean operational strategic planning tool. The current research combines SD, $\mathrm{BMC}$ and lean.

\section{Literature review}

2.1 Concept of business model and its representation In the 1990s, the Internet revolution triggered the introduction in the business jargon of a novel term: the business model (Zott et al. 2011). In the present research, business models are understood as interdependent activity systems, which describe the three mechanisms of value 
capture, value proposition and value creation and delivery inherent in every organisation. In recent years, business models have become a new unit of analysis for organisational strategy. Duarte and Cruz-Machado (2013) provide a comprehensive list of business models that are used in relation to lean manufacturing. These include The European Foundation for Quality Management model, The Shingo Prize model, The Malcolm Baldridge Award and International Standard ISO 9001. These models are typically award-based, are involved and the maturation period can extend months and even years. Others are specialized, such as Six Sigma and are useful where one needs to focus on specific areas for example Quality Management. Zott and Amit (2013) recognise the study of the dynamics of business model evolution as a great promise to enhance the understanding of how organisations create and capture wealth. Abdelkafi and Täuscher (2016) demonstrated in their work the potential of SD modelling applied to capturing the dynamics of business models, in the context of sustainability. Nevertheless, they did not specifically describe methods for depicting the business model of an organisation.

Osterwalder and Pigneur (2010) designed the well-known Business Model Canvas (BMC) - illustrated in Figure 1. The nine basic building blocks of this tool graphically describe the rationale of how a business creates, delivers and captures value. The reasoning behind the BMC is that a company's overall business can be mapped using nine key building blocks: customer segments that describes those who pay for the company's goods and services; value proposition that defines the underlying customer value such as quality and pricing; channels through which the customers are serviced; the customer relationships that the company has to establish to ensure customer value is sustained; the revenue that is generated through selling to the customer; the key resources that are used to deliver value; the key activities such as production, finance and sales/marketing; key partners the company works with such as suppliers and the cost structure of the business i.e. what adds to the cost of providing the value to the customer.

The BMC is a simple, relevant, and intuitively understandable tool for describing and analysing business models and has found acceptability in many organizations. However, the BMC on its own is limited in the sense it that it fails to capture the dynamics of business interrelationships. Moreover, it does not indicate the future state of the business. These limitations can be overcome by applying computational modelling methods such as system dynamics.

Figure 1. The Business Model Canvas (Osterwalder and Pigneur, 2010) 
2.2 System dynamics modelling as a complimentary tool in organizational research

As defined by sterman (2000), "system dynamics (SD) is a perspective and set of conceptual tools that enable us to understand the structure and dynamics of complex systems". It has demonstrated its potential to capture long-term side effects of decisions, speed learning, develop our understanding of complex systems, and design structures and strategies for greater success (Sterman, 2000). Thus far, several studies have applied SD modelling to a wide range of challenges related to lean supply chain, manufacturing productivity, cost performance and change management, among several other topics (Rodrigues and Dharmaraj, 2006; Uribe, 2008; Carvalho et al. 2011; Deif and ElMaraghy, 2014).

system dynamics has been repeatedly applied as a complementary modelling tool. For instance, Reiner (2004) combines SD with discrete event simulation (DES) for designing business processes. Furthermore, previous investigations have demonstrated the usability of SD for overcoming the limitations of traditional management tools; such as, Business Process Flow Chart, Balanced Scorecard and Business Model Canvas (An and Jeng, 2005; Zhang and Li, 2008; Camila Romero et al. 2015). In a recent research, Groesser and Jovy (2015) aimed at capturing the business model of a company in the e-commerce sector, using SD.

There have been very limited studies, such as Groesser and Jovy (2015), Abdelkafi and Täuscher (2016), that have applied SD to study firm-level business models. None of them propose a detailed and structured method for translating a business model into a firm-level system dynamics (SD) model. Therefore, the construction of such SD models for other investigations seems difficult to replicate.

\subsection{Assessing the impact of lean manufacturing strategies}

Lean manufacturing is often promoted as a means of improving organizational performance (Stone, 2012), even though the principles direct one to focus on customer value enhancement through the elimination of waste and improvement of flow (Cudney and Elrod, 2011). Shah and Ward (2003) have to date provided one of the most comprehensive list of lean manufacturing practices, tools, bundles and performance indicators.

Lean metrics are the measurement items for tracking the performance of lean practices (Oleghe and Salonitis, 2015). Examples in the literature include machine breakdown frequency for Total Productive Maintenance practices (Oleghe and Salonitis, 2016); time to adjust production for 
Manufacturing Flexibility (Ali and Deif, 2016); defect rate for Quality Management (Omogbai and Salonitis, 2016) and manufacturing cycle time for Kanban (Roth and Franchetti, 2010)

A number of tools and methods have been promoted for investigating lean manufacturing and its performance (Oleghe and Salonitis, 2018). Topmost are those that guide one through various stages in a lean transformation journey such as the Lean Enterprise Self-Assessment Tool (LAI, 2012). These methods provide one with a holistic snapshot of current as-is lean state. If one required a more detailed analysis and to project the impact of lean interventions into the future, simulation modelling is often advised (Robinson et al. 2012).

Investigating lean manufacturing on the basis of simulation modelling has been made possible using discrete event simulation, system dynamics and agent-based modelling (Ali and Deif, 2016; Omogbai and Salonitis, 2016; 2017; Frazzon et al. 2017). Rarely are the simulation-based investigations concerned with the company's overall business strategy, for example, looking at how lean manufacturing efforts can be used to improve market share and profitability.

Table I has been used to indicate the representative works on SD/BMC; lean manufacturing/SD and lean manufacturing/BMC. We did not find any studies combining SD, BMC and lean manufacturing. There seems also to be a paucity of studies in the area of using SD to assess the impact of lean manufacturing on overall business strategy and performance.

Table I. Representative studies relating to SD/BMC, Lean/SD and Lean/BMC

\section{Modelling methodology}

The present modelling methodology was designed according to the principles indicated by sterman (2010). The ultimate goal of the procedure is to develop a SD model for assessing the consequences of introducing strategic initiatives for a firm's business model. Fig. 2 summarises the proposed modelling methodology applied in the present study .

Figure 2. The proposed modelling methodology

\subsection{Depict Canvas Business Model}

The content of the SD model is grounded on the BMC of the firm. Completing the nine building blocks of the BMC (Fig. 1) would generate an effective depiction of a firm's business model. The managers of the company provide this 
information and, therefore, the resulting capture of the business model is subjected to the managers' understanding of the organisation.

\subsection{Define the target strategy}

As sterman (2000) argues, SD models must address a specific and clear goal, and simplify rather than try to reproduce whole systems in detail. Thus, a clear definition of the strategic initiative under analysis is required at the very beginning of the modelling process. Managers have to describe the specific strategy that the firm is willing to implement. Besides, the consequences of the policy for the different elements of the business model might be outlined at this phase. This way, the purpose and scope of the SD model are determined, and then the time horizon is established accordingly.

\subsection{Divide into sub-models: value proposition, value creation and value capture}

Bocken et al. (2015) condensed the BMC into three subgroups with which one can place the nine building blocks of the BMC. These three subgroups include Value Proposition (consisting of the value proposition, the customer segments, customer relationships and the channels), Value creation (consisting the key resources, key activities and key partners) and Value capture (consisting the cost structures and revenue streams).

The value proposition denotes the value offered by the firm to its customers: what value is provided and to whom? Note that the value proposition can be interpreted as the value perceived by the customers, or, on the contrary, can be defined from the firm's viewpoint as a measure of its competitiveness (Bocken et al., 2015). The present research takes the value proposition with regard to the customers' perspective, since it relates more closely with the lean manufacturing strategy that is being considered by the case study company. Value creation is operationalized as the firm's capacity of creating value and derives from its key resources and processes: how is value provided? The value capture represents the value that the firm generates for itself from its value proposition: how does the company make money or others forms of value? Overall, these three mechanisms of value proposition, value creation and value capture are generic and are present in most, if not all, organisations. Abdelkafi and Tauscher (2016) went further to develop a SD-based Business Model for Sustainability, using these three subgroups as the foundational building blocks upon which their SD model was built. The condensed BMC presented by Bocken et al. (2015) which Abdelkafi and Tauscher (2016) later on modelled using SD, provides one 
with a basis for conceptualizing the SD model in the proposed modelling methodology.

3.4 Establish variables and stock and flow structures Once the firm's business model and the SD model scope have been defined, the next step consists of expressing the business model into the SD notation. The aim is to determine relational dynamic hypotheses and build causal loop diagrams and stock and flow diagrams. Managers and modellers have to work in conjunction to devise plausible cause and effect relationships. These associations can be set within or between the sub-models. While the BMC serves as the basis for the SD modelling concept, the SD models would still need to be used to address specific problems. The nature of the problem and the context defines the key variables to include and exclude from the models (Sterman, 2000). For example, a company may use various channels to reach its customers, however, one or a few would account for majority of channel activities. It may be expedient to model the major ones and not all channels in the SD model for the company.

\subsection{Construct the SD model}

This phase involves testing the dynamics hypothesis of the previous stage. The sub-models are linked and the system is evaluated as a whole. Estimated data is here inputted into the model for performing reality checks of the model behaviours. As a result of the testing process, the modelling becomes at this point an iterative procedure, in which hypotheses of the prior phase are constantly reviewed and reformulated. This process continues until a fully formal model, complete with equations, parameters and initial conditions, is reached.

3.6 Verify and validate formally the SD model

No model can be accepted unless it has been formally validated, since the process of validation is vital to establish the credibility of the model (Martis, 2006). Forrester and senge (1980) identify a set of tests which are considered as core tests in SD. Structure Verification Test consists of double-checking whether the model conforms to the specifications and assumptions about the structure of the business, and have most of its relevant elements. Dimensional Consistency Test verifies whether all equations are dimensionally balanced. Most SD software come with standard features for checking dimensional consistency- a tool for detecting dimensions' discrepancies in the equations. The model is subjected to this test for challenging the consistency of the equations. These two tests have been selected due to their potential to verify whether the model has been correctly implemented as a 
whole. They confirm the structure of the model and the reliability of the relationships between variables.

Extreme conditions check tests every equation in the model to ensure they make sense even if subjected to extreme but possible values of variables. This test showed that every equation in the SD model reproduces concrete relationships within the company, under positive values of the variables. Negative values do not reflect the reality of the business and, therefore, the equations are not reliable under such negative figures. The inherent nature of the equations does not allow the variables to take negative values in any case.

The boundary adequacy test verifies if the model structure is appropriate for the identified problem. The model aims to assess how lean manufacturing improvements could affect the case company, specifically, to the customer population, the value propositions and the production process. The relationships between these elements are captured in the model, so that the feedback effects between them can be observed over time. The mechanisms by which the market grows or decreases are not considered to be relevant for the model purpose. In the same way, the monetary and time investment in lean manufacturing policies has not been included in the model. The interactions between the case company and the suppliers have been omitted from the model, since supplier management enhancements would not be implemented within the target time span of the model

Extreme-Condition Sensitivity Test determines whether extreme shifts in parameters can cause model to fail behaviour. These extreme conditions do not normally occur in real life, but the resulting model behaviour can be easily predicted. Thus, the confidence in the model is enhanced if the model behaves as expected. The suitability of this test for validating SD models have been widely recognised in the literature (Uribe, 2008).

3.7 Simulate the model: baseline and target strategy

Once confidence is developed in the model, the model becomes a powerful tool for evaluating the consequences of introducing strategic initiatives for the organisation's business model. The model should be simulated under the current scenario, and then evaluate the outcomes of introducing the target policy. Several situations can be assessed by just varying the model parameters.

3.8 Interpret results and recommend policies

Finally, the results have to be critically considered for providing fruitful insights about the realm of the organisation's business model. The robustness and sensitivity to uncertainties of the recommended strategies 
must be valued.

\section{Case study demonstration of the designed methodology}

A case study approach was adopted to conduct this research. The case study company is an SME print packaging manufacturer that primarily produces printed labels and wrapping solutions. The company initiated to embrace lean manufacturing principles about 3 years ago as a means of sustaining business growth and competitiveness. Currently, customer orders are predicted to grow by $20 \%$ in the next two years. Yet, it is not intended to increase manufacturing capacity by adding more machines or production shifts. Rather, the company sought to improve the performance of its lean manufacturing practices, but needed to know what the likely impact on its business performance would be. Performance of its lean manufacturing was gauged along the following lean metrics namely: reduction in machine breakdowns, defect rate, manufacturing cycle time, as well as improvement in production schedule and manufacturing flexibility. By first establishing how improvements in these parameters would impact overall business performance, the company could thereafter pinpoint specific lean practices to implement or improve.

Fig. 3 shows the estimated pattern (reference mode) for manufacturing lead time and market share for the case study, if the strategy is one that maintains status quo. An exponential trend is predicted because the manufacturing operations would increasingly find it difficult to cope and customers would gradually be dissatisfied as lead time increases. Ideally the reference mode should be generated from available quantitative data (Elias, 2016). It is also possible to estimate behaviour over time using qualitative information that is available about the system (Sterman, $2000)$.

Figure 3. Reference mode showing pattern of manufacturing lead time for a strategy to maintain status quo

4.1 Construction of the SD model

Key employees in the company participated in building the BMC for the company. The key employees included the managers in the production, sales, supply chain and finance. They were asked to provide information relating to the BMC building blocks. For example, the Sales Manager provided information regarding the various sales channels used as well as the key customer requirements. The Finance manager provided information about the cost structure. The engagement of the managers increased their participation and interest in the model building which encouraged them to add further inputs. The participation of the managers enabled the model to be validated as it was being built and 
also helped them understand its purpose. It took roughly a week to get the necessary inputs to build the BMC for the company, which was one of the reasons for using a top-level quick turnaround tool such as the BMC. Subsequent data needs for coding the eventual SD model were collected later on whereby the managers involved were asked to provide information specific to coding the model. In a way, the BMC and the SD model provided one with a structured data collection approach. Fig. 4 shows the eventual BMC that was generated for the case study.

\section{Figure 4. Business Model Canvas of the Case Company}

The generic structure of the three value exchanges was embedded into the SD model. The approach enabled partial modelling and organised the content of the BMC in the SD model. This way, the subsequent construction of the SD model was simplified and streamlined.

The SD model was constructed using the software AnyLogic 7.3.4. Figure 5 shows the value proposition sub-model. The process of new customer acquisitions was represented through the widely-accepted Bass Diffusion Model. The stocks Potential Customers and Customers represent the total population in the market, which raises at the rate of Market Growth. New customers are adopted from the stock of Potential Customers at the Adoption Rate. At the same time, the pool of Customers is depleted at the Loss Rate, which depends on the Customer Loyalty. Two variables define the Adoption Rate; on the one hand the Adoption from Agents variable reproduces the communication between sales agents and third-party customers; moreover, the adoption of certain customers is driven by word of mouth (WOM).

Figure 5. Value proposition sub-model for the case company

Furthermore, the value proposition, as seen by the customers, was constituted by six variables that shaped the overall Customer Satisfaction. Following the guidelines of Kristensen et al. (1992) 'On measurement of Customer Satisfaction'. Table II was constructed for defining the elements relevant for the value proposition. The relative importance of each factor was determined by the case company managers, as well as the potential performance indicators for its measure.

Table II. Elements of the value proposition

Fig. 6 shows the value creation sub-model. The Order Backlog stock is the difference between the Order Entry 
Rate and the throughput. When customers place job orders, they are advised of an Agreed Lead Time to completion which includes a certain safety Production Cushion to reduce the risk of late deliveries. All the while, the product of the Order Backlog by Cycle Time determines the Target Lead Time as seen by the production process, which is also affected by the Order Size. The Desired Throughput is then scheduled according to the level of the Order Backlog and the Target Lead time. Finally, the Throughput takes the value of the Desired Throughput after the delay correspondent to the Time to Adjust Production. However, the Defect Rate, Breakdowns and the Mean Time to Repair variables constantly alter the Throughput.

The inverse of the cycle Time, measured in time between produced orders, equals to the maximum Capacity. The Capacity Utilisation is then determined by the Throughput rate and the time wasted due to defects and breakdowns. When the Capacity Utilisation reaches $100 \%$ the Order Entry Rate is limited as the system is not able to further increase production.

Figure 6. Value creation sub-model for the case company

Lastly, Fig. 7 depicts the mechanism of value capture. The Accumulated Profit stock is filled by the Profit of each month, which depends on the orders delivered and the Profit per Orders - difference between the Revenues per Order and the cost per Order. The revenues structure is formed by the direct sales at a certain Price and the shipping service to customers at a Dispatch Service Price. The costs structure has been simplified into Manufacturing Cost and Other Costs associated per order produced.

Figure 7. Value capture sub-model for the case company

Fig. 8 depicts the business model of the case company in SD notation, where the value proposition, creation and capture sub-models have been interconnected.

Figure 8. System dynamics model of the case study company depicting its business model

The Adoption Rate of customers, as explained before, is the sum of the rates of Adoption From WOM and Adoption from Agents (see Eq. 1).

$$
\text { AdoptionRate }=(\text { AdoptionFromAgents }+ \text { AdoptionFromWOM })
$$


The Agent Effectiveness is defined as the fraction of the Potential Customers population that place an order as a result of the advertising of the sales agents (see Eq. 2)

\section{AdoptionFromAgents $=$ PotentialCustomers $*$ AgentEffectiveness}

The WOM effectiveness and the Adoption From WOM are similarly related. The Loss Rate (see Eq. 3), the ratio at which the Customers stock is emptied, is determined as the percentage of customers that do not repurchase (i.e. 1Customer Loyalty). However, this effect is not instantaneous, since an unsatisfied customer would take certain time to look for another printed packaging provider. This delay in time was approximated to 6 months.

$$
\text { LossRate }=\operatorname{delay}\left(\left(\text { Customers } * \frac{1-\text { CustomerLoyalty }}{100}\right), 6\right)
$$

The formula for the Customer Loyalty was approximated to be a linear function of the Customer Satisfaction (see Eq. 4), as proposed by Reiner (2004). This relationship is only significant in the case of small changes in customer satisfaction.

$$
\text { CustomerLoyalty }=0.75+0.58 *\left(\frac{\text { CustomerSatisfaction }}{100}-0.67\right)
$$

As regards the calculation of the Customer satisfaction, each of the selected value propositions appear in the formula as 'Variable Value * Variable Weight' (these weights were exposed before in Table II). The values of all these variables were determined using Table Functions, which are tables of values used for specifying non-linear relationships. Table Functions are easily illustrated with an example: Relative Lead Time (Eq. 5). was defined as follows:

$$
\text { RelativeLeadTime }=\frac{\text { AgreedLeadTime }}{\text { MarketLeadTime }}
$$

The Table Function for the Relative Lead Time takes the value of the Eq. 5 as an argument. Then, as seen in Fig. 9 (Table Function for the Relative Lead Time), the table returns a value between 0 and 100 corresponding to the resulting value for the Customer Satisfaction. The profile of the curve intends to capture the effect of the relative lead time to the customer satisfaction. If the lead-time is close to the market lead-time, the effect on customer 
satisfaction is minor. Yet, the influence in the customer satisfaction grows exponentially as the difference between the two lead-times is more significant. The specific correspondence of figures between relative lead-times and customer satisfaction was adapted from Uribe (2008). For the other value proposition elements, the same non-linear relationship and correlations to customer satisfaction changes were established.

Figure 9. Table Function depicting the relationship between customer satisfaction and relative lead time

Equation 6 shows how the Table Function is called in Anylogic for the Relative Lead Time versus Customer Satisfaction relationship.

\section{CustomerSatisfaction $=(\ldots)+$ RelativeLeadTime_lookup_.get ( RelativeLeadTime $) * 0.16+(\ldots)$

The Order Entry Rate was calculated as showed in Eq. 7 . It is considered that every new customer places one first order. Thus, the Adoption Rate equals to an Initial Purchase Rate as seen by the production system. Approximately, the 17.5\% of the customer pool place orders recurrently at a Regular Purchase Rate, whereas the other 82.5\% purchase irregularly - the Non-Regular Purchase Rate was assumed to be one order per year. These proportions were taken as constant over time. The Order Entry Rate was defined as the sum of the three order rates:

\section{OrderEntryRate $=$ RegularPurchaseRate $*$ Customers $* 0.175+$ NonRegularPurchaseRate *Customers $* 0.825$ + InitialPurchaseRate}

The case company provided raw data about the frequency of order entry. The software stat:Fit Version 3 was used to approximate the dataset into statistical distributions. The continuous distribution that best fitted was the lognormal (see Eq. 8).

TimeBetweenOrders $=$ lognormal $(0.0814,0.958,0.238)$

Once the Time Between Orders was determined, the definition of the Regular Purchase Rate per customer was straightforward to define (Eq. 9).

$$
\text { RegularPurchaseRate }=\left(\frac{1}{\text { TimeBetweenOrders }}\right)
$$

When job orders are placed, the product of the Order Backlog by the processing Cycle Time determines the Target 
Lead Time for production (see Eq. 10). However, it is possible that there are no orders queuing in the backlog. In such case, the time to delivery equals to the Minimum Lead Time to produce one order.

TargetLeadTime $=\max ($ MinimumLeadTime, CycleTime $*$ Order_Backlog $)(10)$

Then, the Agreed Lead Time offered to customers (see Eq. 11) is calculated as the Target Lead Time plus the safety Production Cushion.

$$
\text { AgreedLeadTime }=\text { TargetLeadTime }+ \text { ProductionCushion }
$$

The Desired Throughput is the rate at which orders should be manufactured (see Eq. 12) Therefore, the division of the number of orders in the order Backlog by the current Target Lead time, provided the desired rate of production. The real Throughput (see Eq. 13), also specified in orders per month, was obtained by applying a delay to adjust production and the effects of the defects and breakdowns.

DesiredThroughput $=\frac{\text { Order_Backlog }}{\text { TargetLeadTime }}$

Throughput $=\operatorname{delay}($ DesiredThroughput $*(1-$ DefectRate $) *(1-$ RepairDow ntime),TimeToAdjustProduction)

The maximum Capacity (see Eq. 14) is measured in orders per month, and could be easily obtained as the inverse of Cycle Time. The production system is considered to be busy when manufacturing job orders, repairing faulty equipment and re-processing orders with defects. Then, the capacity Utilisation can be calculated as follows (see Eq. 15).

$$
\begin{aligned}
& \text { Capacity }=\frac{1}{\text { CycleTime }} \\
& \text { CapacityUtilisation }=100 *\left(\frac{\text { Throughput }}{(1-\text { DefectRate } *(1-\text { RepairDowntime })}\right) \\
& \text { Capacity }
\end{aligned}
$$

Throughput represents the rate of shipped orders to customers per month. Consequently, the Profit per month (see Eq. 16) was determined by multiplying the throughput by the equivalent Profit per Order.

$$
\text { Profit }=\text { Throughput } * \text { ProfitPerOrder(16) }
$$


The Revenues per Order were defined as the sum of the Price of one order plus the additional expenses for the dispatching service (see Eq. 17). The parameter of Dispatch Service Price was set as a percentage of the selling Price. Besides, only the fraction of customers indicated by the Dispatch Service Rate procured the service. The Cost Per Order (see Eq. 18) and Profit per Order (Eq. 19) were determined as follows:

\section{RevenuesPerOrder $=$ Price + DispatchServicePrice $*$ Price $*$ DispatchServiceRate}

\section{CostPerOrder $=$ ManufacturingCost + OtherCosts}

$$
\text { ProfitPerOrder }=\text { RevenuesPerOrder }+ \text { CostPerOrder }
$$

Appendix 1 and 2 contains the full list of parameters and governing equations used in the current study.

4.2 Verification and validation of the SD model

The SD model structure captures the structure of the case company business. The model architecture has been developed grounded on the information provided by the case company and organizational relationships found in relevant literature. The SD model is founded on generic sustainable business model logic as proposed by Abdelkafi and Tauscher (2016). The BMC has been validated by the case company and depicts the main elements of the system such as value proposition or cost and revenue structures. The production planning has been modelled based on the relational diagram built to capture the specific decision-making process. concrete relationships and dynamic variables have been extracted from closely related research papers.

Based on the aforementioned, the model structure conforms to the knowledge about the structure of the business, and have most of its relevant elements. Therefore, the SD model is consistent conceptually to the reality of the business.

Key variables from the sub-models of value proposition and value creation were chosen for the tests, since they are central for the lean policy evaluation. For each test, the variable is established at its defined minimum and maximum. The model passes the test if it behaves as expected. We performed a variety of extreme tests on the model and found that the overall trends in the model do not change as consequence of parameter variations. The behaviours are exaggerated or moderated in congruence with 
the modification of the model variables. Therefore, the model approves the extreme behaviour-sensitivity test, and enhances the confidence in the model behaviour.

\subsection{Simulation results}

The specific aim of the SD model was to assess impact of lean improvements on the business performance. The proposal of simulation experiments naturally stems from this goal. In other words, the scenarios were precisely designed to address the ultimate model objectives. Table III presents an overview of the simulation experiments. The modification of the model parameters enables one to generate the specific conditions for each experiment (Omogbai and Salonitis, 2016). These parameters are independent of other variables in the model.

Table III. Simulation scenarios to test with the SD model

The parameters were specifically chosen to characterise the effects of the lean improvements. Both the case company managers and other studies in the literature (Pellow et al. 2003; Uribe, 2008), identified delivering on time as a critical factor for the satisfaction of customers. In fact, keeping lead-times below 3 days was a key performance goal for the case company. Consequently, the minimisation of lead-times was considered as a central objective of the lean practices. Out of the key lean improvements identified in the target strategy, five of them were selected as pertinent to illustrate the lean policies and their effects in the model. These included decreasing defect rates; minimising machine breakdowns; reducing the time to adjust production; improving the delivery safety time cushion; and reducing cycle times. The selected parameters are believed to be sufficient enough to exhibit the outcomes of the intended lean strategy for the case, since they account for majority of what affects manufacturing lead time (Uribe, 2008; Omogbai and Salonitis, 2016).

The simulation run time is set at 60 months (five years), which is the period covered by the forecast of demand growth of the case company - from year 2016 until 2021. The selected time horizon is adequate for the model purposes, since it is long enough for introducing modifications in the business processes and for evaluating the consequences of the policies for the business. Months are the time unit for the simulations.

4.3.1 Scenario 1: Current baseline

The objective of this first experiment is to understand how the business 'as-is' would react to the increasing demand. In strategy management, there is always an option of doing 
nothing. For example, in the present study, this choice would be the most suitable in case all the other considered strategic initiatives resulted in worsening the business performance.

Fig.10a shows the evolution of the order backlog for the base run. The backlog stock is a key component for the production system since it directly determines the lead time to ship orders - the greater the backlog the longer the lead time. As can be seen, the backlog increased gradually from month 15 onwards, which indicates that the capacity utilisation reached its maximum at this point in time. Calculations of the maximum capacity support this: total installed processing capacity is approximately 525 job orders, yet the real capacity oscillates between 340 and 400 job orders due to waste and delays. On average, the initial order entry rate per customer is 0.38 - 995 customers generate around 380 monthly job orders. After 15 months, the number of customers is expected to reach 1095an estimated growth of $10 \%$-, which approximates a total of 416 monthly orders. Thus, the real processing capacity would be exceeded in about a 15-month period. Besides, it is interesting in this graph that fluctuations of the backlog level became larger between the months 15 and 60 . This suggests that the production system, when fully loaded, is more vulnerable to variations of the demand.

Fig. 11 a compares the lead time and the agreed lead time for the scenario 1. Logically, the lead time and the agreed lead time variables replicated the oscillations of the order backlog. Interestingly, from Figure $11 \mathrm{a}$, the difference between the two lead times diminished as the production system was overloaded during the last months. The explanation for this is that the lead time offered to customers only depends on the order backlog and the installed capacity, while the real lead time is a function of the throughput. The influence of the breakdowns and defects is more significant in a fully loaded production system.

Throughput remains unchanged (see Figure 12a), constrained by the production capacity. This is likely if there are no improvements, and the company carries on with the status quo. As can be seen from graph Figure 13a, the customer satisfaction decreases slightly from month 15, due to the longer lead time. In turn, after a certain period of time, the market share drops steadily (Figure 14a). The overall response of the system can be inferred from the evolution of the market share. The results of the baseline scenario, as shown in Figure 14a, suggests that the production might sustain business growth in the short term. Nevertheless, the case company might not remain leader in its market as it will not be able to cope with the increasing demand in the long run. 
Figure 10. 5-year trend depicting the order backlog: (a) current baseline; (b) scenario 2.1; (c) scenario 2.2 ; (d) scenario 2.3

Figure 11. 5-year trend depicting the lead time: (a) current baseline; (b) scenario 2.1; (c) scenario 2.2; (d) scenario 2.3

Figure 12. 5-year trend depicting throughput: (a) current baseline; (b) scenario 2.1; (c) scenario 2.2; (d) scenario 2.3

Figure 13. 5-year trend depicting customer satisfaction index: (a) current baseline; (b) scenario 2.1; (c) scenario 2.2 ; (d) scenario 2.3

Figure 14. 5 -year trend depicting market share: (a) current baseline; (b) scenario 2.1; (c) scenario 2.2; (d) scenario 2.3

4.3.2 Scenario 2: Implementation of lean manufacturing practices

The case company initiated a lean manufacturing programme about three years ago. As is with lean, there should be continuous improvement. For example, to reduce frequency of machine breakdowns the managers can upskill machine operators to undertake routine maintenance (Aspinwall and Elgharib, 2013; Jain et al. 2014). Defect rate can be reduced by systematically implementing the Six Sigma DMAIC methodology, for example (Jirasukprasert et al. 2014). Improving scheduling to minimize breaks and idle time (Roth and Franchetti, 2010) are ways that can be used to improve the production cushion and time to adjust production. Through the implementation of $5 \mathrm{~S}$ to reduce the time workers spend looking for setup tools is one way to significantly reduce setup time and improve manufacturing cycle time (Omogbai and Salonitis, 2017)

The model parameters are now adjusted to reproduce the situation of applying the above stated lean manufacturing improvements into the production system. Likely values of the production improvements (scenario 2.1, Table IV) have been assigned based on relevant lean manufacturing literature (Pavnaskar et al. 2003; Filho and Barco 2015) and the case company managers' experience. This approach is in line with the 'Framework for choosing among different lean-based improvement programs', where Filho and Barco (2015) propose to estimate the magnitude of possible improvements based on experiences of employees and the knowledge present in literature. This former study also considers lean improvements to progress in an exponential decay over time, which has been applied as well in the present research. 
Two more experiments have been run under this configuration, namely, a pessimistic valuation of the lean manufacturing enhancements (scenario 2.2, Table IV) and an optimistic one (scenario 2.3, Table IV). These two scenarios are meant to test the sensitivity of the improvements of the lean policies.

Table IV. Modifications of the model parameters for scenario 2

The simulation results indicate that the backlog is steady and flat for scenarios 2.1 (Fig. 10b) and 2.3 (Fig. 10d), whereas the experiment 2.2 (Fig. 10c) resulted in a slow ramp of the order stock level. This indicates that, in case the lean improvements were partially realised, the production process could hardly assimilate the external demand over time. Lead times remained constant as expected, and agreed lead time tended to incline to the values of actual lead time since the production cushion was being progressively reduced - see Figure 11b to d. Both figures therefore indicate that the lean enhancements augmented throughput sufficiently, see Figures 12b-d. Two mechanisms influence the throughput. Firstly, the production capacity grows as a result of the cycle time decreasing; secondly, the improved defect and breakdown rates contribute to augment the effective capacity by eliminating waste.

Regarding the customer satisfaction, the lean strategy included improvements to three of the components that directly impact on the customer satisfaction variable, namely: the printing quality in terms of print clarity and sharpness, lead time and on time shipments relative to other producers. As observed in Figure $13 \mathrm{~b}$ to $\mathrm{d}$, the shrinking tendency of the customer satisfaction in the base run changed for the lean scenario. The outcomes of the experiments clearly demonstrate that the lean production would positively affect to the customer satisfaction. Conversely, the results also suggest that the effects of the lean practices might be insufficient for rising the levels of customer satisfaction significantly.

Lastly, Figure $14 \mathrm{~b}$ to $d$ shows that the market share continued upward for the three experiments under the lean improvement situation. The scenario 2.2 (Fig. 14c) showed a slowdown of the market share towards the month 60. This suggests that a reduced efficacy of the lean practices could result into capacity overloads of the production system. Overall, these results indicate that the consequences of lean production contribute to maintain business growth and competitiveness in both the short and long term.

4.3.3 Scenario 3: Optimisation of lead time 
For the present study, the optimisation experiment consisted on finding the optimal set of lean improvements that minimised lead-times. Therefore, the objective function was set to minimise lead time. Table V presents the maximum and minimum values for each parameter included in the test. Logically, those parameters are the ones previously identified as representative of the lean improvements in Table III. For the optimisation experiment, the type of every parameter was specified as continuous since the model aimed to evaluate behavioural patterns over time. In order to avoid the initial distortions of the simulation launch, a requirement of accumulated profit higher than 750 was set in the configuration of the test.

Table V. Parameter ranges for the optimisation scenario

The optimisation experiment was run for 500 iterations. For each iteration, the optimisation algorithm varies the parameter values, evaluates if the resulting lead-time is the minimum so far and checks whether the solution meets the requirement for the accumulated profit. The objective function did not improve significantly after 383 iterations.

The optimum lead-time was 0.129 months (3.87 days). To minimise lead time requires augmenting the throughput while maintaining the level of the backlog low. As expected, the lowest breakdown and defect rates and the maximum value for capacity turned into the best possible lead time, since they increase throughput (see Table VI). However, the experiment resulted in a very short production cushion despite the fact that it is not directly connected to the lead time values. Interestingly, the value for the time to adjust production was far from the minimum possible in its range, which is counterintuitive: longer intervals to react to demand changes would result in greater backlog levels. This behaviour can be understood under a situation of complete capacity utilisation. If the system is fully loaded, then it would produce at its maximum rate at every moment and, as a consequence, the time to adjust production would lose relevance.

Table VI. Parameter values for the optimum lead time

In summary, these results suggest that the current business scenario might be insufficient for accommodating the external demand in the medium- and long-term. According to the experiments performed, lean improvements when sustained over time seem to be enough for, at least, maintaining the position of the case company in its market. other experiments could be done by changing the objective function and/or the configuration of parameters. 
Considering previous studies, the next section reviews the results of the model and discusses their implications.

\section{Discussions}

5.1 Modelling methodology

Several prior studies have noted the convenience of combining system dynamics and other modelling techniques, e.g. discrete event simulation, for designing and assessing business processes (An and Jeng, 2005). However, as Reiner (2004) claimed, process performance measures and process improvement initiatives should be evaluated under consideration of broader business aspects such as customer implications. In fact, system dynamics can potentially provide insights about the consequences of introducing a concrete change of a business process for the rest of the firm elements. Recent works have utilised the business model canvas as the foundation of system dynamics models (Camila Romero et al. 2015; Groesser and Jovy, 2015). Meanwhile, Groesser and Jovy (2015) highlighted the pros and cons of using system dynamics modelling as a strategy tool for decision making. As one of the main disadvantages, the complexity of the system dynamics models can be overwhelming for the eventual users of the model.

In consequence, the present study has proposed a novel method for structuring system dynamics models aimed at assessing strategic initiatives at a firm-level. The model has been developed using the method of partial modelling, which consists in dividing a complex model into various smaller sub-parts. For doing so, this research has adapted the stock and flow diagram of a generic business model logic as suggested by Abdelkafi and Täuscher (2016) in their article about business models for sustainability. Therefore, the proposed model structure has been divided into three sub-models, specifically, customer value proposition, value creation and value capture sub-models. A reinforcing feedback loop between each pair of them governs the growth of a generic firm. This general structure has been embedded into the modelling methodology applied in the study .

At the same time, the specific dynamic variables and their relationships have been determined based on the strategic policy to be assessed and the canvas business model of the firm. The nine elements of the canvas business model fall neatly into the three sub-model structures (Bocken et al. 2015). To the author's knowledge, the combination of these two tactics, the tripartite structure of generic business model logic and the canvas business model, has not been applied before in system dynamics modelling. This novel approach presents several advantages. 
- Firstly, it reduces the complexity for the modeller of building a firm-level model as it initially provides a configuration for the model and divides it into smaller sub-models.

- Second, the method takes advantage of the canvas business model for both collecting data, and structuring the model variables associated to each element of the canvas.

- Third, due to its simple structure, the model facilitates the final users' understanding of its behaviour and therefore fosters its usability.

- Lastly, the business generic nature of the modelling method makes it applicable for any firm.

A case study approach was adopted to conduct this exploratory study. The system dynamics model set out with the aim of assessing the consequences of introducing lean manufacturing into a print packaging manufacturer.

\subsection{Insights from the case study}

Once the system dynamics model was developed and validated, real data from the case company was inputted in order to perform experiments under different prospective scenarios. The following findings emerged from the simulation results.

The level of the order backlog fluctuated progressively more over time. This suggests that the production system, when fully loaded, is more vulnerable to variations of the demand. The growth trend of the market share quickly decayed and ultimately turned into a declining tendency. It is possible, therefore, that the case company might not remain leader in its market under these conditions, as it will not be able to cope with the increasing demand in the long run.

These conclusions are in agreement with those obtained by Uribe (2008) for a print company, which demonstrate that inflexible processing capacity leads to fluctuations in the production backlog, turn time and on-time service metrics. Also, this previous study corroborates the idea that increasingly higher order volumes result in a collapse of the print processes.

As the throughput maintained moderate oscillations over time, the effects of the lean policies might not be sufficient for sustaining a stable production. This may be due to the randomness of customer order frequency and order sizes. Other results show that lean production would positively affect the customer satisfaction since it improved in the three experiments however marginally, suggesting that the effects of the lean practices might be insufficient to significantly raise the levels of customer satisfaction. This is likely the case since lean manufacturing alone may be insufficient to improve customer 
satisfaction, when other customer needs such as price and dispatch service rate are not addressed as well. Under a pessimistic valuation of the lean manufacturing enhancements, the market share stagnated at a certain point in time. This suggests that the efficacy of the lean practices to improve market share could reduce after a certain time. This is not surprising since market share is not entirely dependent on improved production process only, but on a host of other business initiatives such as discounts and advertisements. In other words, other business-related initiatives such as price discounts and advertisements may be considered to supplement lean efforts if the company is to sustain and even improve its market share in the long run.

These observed limitations of the lean policies are consistent with the research of Done et al. (2011). In the context of resource-limited small and medium sized enterprises (SMEs), they argue that improvement programs, such as lean practices, are unlikely to develop sufficient capability for long-term success in SMEs without external ongoing support. Our findings are also in alignment with those of Netland and Ferdows (2016): that tangible benefits arising from lean implementation may be rapid initially, but tend to taper off on the long-run.

The time to adjust production parameter did not behave as expected, which can be understood under a capacity overload situation. If the manufacturing system is producing at its maximum rate at every moment, then very little adjustments would be necessary. Thus, the time to adjust production would lose relevance for minimising the lead time. Such reasoning was not encountered in relevant papers regarding lead-time improvements (Filho and Barco, 2015).

The type of information that was generated in the current research using the system dynamics modelling could not have been achieved using any other means. An acclaimed tool for investigating the opportunities for lean is the Value Stream Map (VSM). The VSM on its own does not account for the many aspects that the system dynamics approach was able to model, for example the value proposition aspect (see Fig. 7). Meanwhile, many tools for investigating lean such as the Lean Enterprise Self-Assessment Tool (Nightingale and Mize, 2002) and the Lean Sensei Tool (AME 2017), are ideally suited for providing information about the current state of lean in the system, but are imprecise in predicting what the system outcome will be for various lean interventions. Meanwhile, Narayanamurthy and Gurumurthy (2016) contend that future works relating to the investigation of lean should be focused on linking the degree of lean implementation to operational performance. We believe the current research effort is in this direction. 
As initially targeted, the simulation findings help to understand how the case company might perform under the strategy of lean manufacturing improvements. The use of SD modelling in lean manufacturing-related research has been on-going (Thun, 2004; Hallam et al., 2009; Ali and Deif, 2016; Omogbai and Salonitis, 2016; Gupta et al., 2018; Omogbai and Saloniti, 2017). The approach taken in the current study is different because a high-level analysis of the operational dynamics is undertaken, rather than a detailed one. By so doing, data requirements for the model is not as heavy or detailed as would be needed to model the plant operations, for example. With the current approach, decisions concerning the business implication of lean improvements can be quickly taken.

The simulation results provide an indication of how improvements in lean practices would impact overall business performance. For example, if the company was considering increasing its market share, then scenario 2.1 or 2.3 should be considered, see Figure 14. However, because both scenarios return similar market share trends, the company may implement the policy that requires less effort, i.e. Scenario 2.1. This makes better economic sense if less can be made to achieve the same where more may also be used. Table IV lists out the lean improvement scenarios, which can also be used as lean improvement targets per year. So, if the policy is to implement scenario 2.1 where defect rate is to be reduced by $10 \%$ per year, then the plant managers can aim to improve work-related practices that can be used to achieve this target. These may include improving machine maintenance to reduce defective outputs as a result of machine inefficiency and training machine operators on how to prevent defective outputs during processing.

In the current research, a case study has been used to demonstrate an approach for analysing lean manufacturing strategy using system dynamics modelling of the company's business model. The approach itself is applicable to a variety of settings including services and product development. This is because BMC and SD are both widely used modelling and analysis tools and they are not case- or industry specific. Although the SD simulation model was built for the case, it includes variables and concepts that are relevant to most types of production settings. For this reason, we believe the developed SD model is applicable to a variety of production-related cases, irrespective of company size or nature of products.

\subsection{Limitations of the research}

This research has argued that its modelling method can facilitate both the modeller's work of building the model the final users' understanding of the model. However, it is 
important to point out that, because the intrinsic complexity of multi-loop feedback systems, system dynamics are not easy to master (Forrester, 2007b). Furthermore, the findings and interpretations derived from the simulation results should be taken carefully. The modelling process is based on subjective mental models and hypothesised feedback loops, which might be difficult to fully validate. As Sterman (2000) mentions, a central principle of system dynamics is to examine issues from multiple perspectives. For instance, because of its complexity, the investment implications of the lean practices could not be estimated and have not been included in the model in the case study. Hence, the lean strategy should be complemented by a financial assessment. It is also important to notice that the business model canvas does not contemplate every stakeholder in the business. Ideally, the policies under consideration should therefore be object of a broader stakeholder analysis.

System dynamics models can never be comprehensive, modelling is the art of simplification (Sterman, 2000). Consequently, the model boundaries - such as supply chain influences or market growth mechanisms - limit the applicability of the model to just the particular objective of evaluating lean manufacturing policies as means of sustaining business growth. Still, the variables included in the model have been agreed with the case company and then validated through the model development process. The borders of the model are relevant to its purpose and ensure the model scope is feasible. Models are never final but provisional, other variables and relationships could be incorporated to capture further dynamics.

Precisely because the model has been designed to fit for purpose, the evaluation of other different strategies in the case company would require to construct a new system dynamics model. However, if the model objective is to evaluate the consequences of the strategy at a firm-level, the model general structure and some of the defined relationships might remain invariable. This relies on the generality of the applied modelling methodology: the business model canvas captures the key features of the business case, and the reinforcing feedback loops between each pair of them are generic. The present research has just analysed a single case study of a print packaging manufacturer; thus, the model might not be significant for other businesses. Yet, the modelling approach is generic and potentially applicable to any other business scenario.

Lastly, SD like other simulation modelling methods, requires one to set the model scope i.e. what is exogenous and what is endogenous (Sterman, 2000). In simulation modelling, one cannot completely rule out the effect of model uncertainties as a result of changes in variables 
considered as out of scope such as changes in manager and worker behaviours and attitudes towards lean or the effect of competitors adopting similar strategies. The fact that these were not modelled does not mean they do not or cannot impinge on the business and overall performance. It simply gives one the impetus to use the baseline top-level model presented in the current study to delve into more detail if one needs to model other factors. So, in a way, the system dynamics approach enables one to validate strategic business plans, before developing detailed operationallevel details. Using the approach described in the current study to progress from the strategic to the operational level would be an interesting area to research further.

\section{Conclusions and future outlook}

The main goal of the current study was to assess the impact of lean manufacturing strategies on business performance, taking into consideration the business model of the organization. A case study was used for this purpose; the key components of the business were depicted using a business model canvas. The system dynamics model was developed according to stock and flow diagram of a generic business model logic. The model was used to establish the operational and competitive outcomes of various lean improvement strategies. The research provides a framework for applying the modelling method, which contributes to the field of knowledge. From the case study findings, it is recommended that the case company further improve lean practices performance as a way of improving manufacturing performance. This would indirectly improve business performance in the area of customer satisfaction and market share in the short-run. In fact, the BMC can be amended such that the value proposition is focused more on lean manufacturing practices. In the long term, lean practices improvements may have only marginal impact on business performance, and the company may need to look elsewhere such as price discounts and improved delivery rate, if the long-run business performance is to be sustained or improved. The detailed lean implementation plan that would lead to the expected improvements in business performance for the case company is being considered in future works.

Although the present study is based on a single case study, it serves as an empirical example of a real business applying system dynamics as a strategic planning tool. More research is needed to state that the businesses applying system dynamics systematically produce better results than those that are not using it (Groesser and Jovy, 2015). The proposed modelling method should be repeated in other businesses to validate its benefits. Future investigation might explore how the system dynamics models could be used 
in conjunction with traditional tools for analysing business strategies.

The manufacturing operations of the case study is a maketo-order type for print packaging production. Although the SD model was built with generality in mind, it remains to be reproduced in other settings to test its replicability. A number of business models are used for assessing lean implementing organizations such as Shingo Prize Model, European Foundation for Quality Management Model, Malcolm Baldridge Model and Balanced Score Card. It would be interesting to know how these models can be elaborated using SD the way the BMC was elaborated in the current study, and used to establish the impact of lean improvements that have been suggested using the models.

\section{References.}

Abdelkafi, N. and Täuscher, K. (2016) 'Business Models for Sustainability, From a System Dynamics Perspective', Organization and Environment, 29(1), pp. 7496. doi: $10.1177 / 1086026615592930$.

Ali, R. and Deif, A. (2016) 'Assessing leanness level with demand dynamics in a multistage production system', Journal of Manufacturing Technology Management, 27(5), pp. 614-639.

An, L. and Jeng, J.J. (2005) 'On developing system dynamics model for business process simulation', in Winter Simulation Conference. 2005. Yorktown Heights, NY 10598, U.S.A. pp. 2068-2077.

Aspinwall, E. and Elgharib, M. (2013) 'TPM implementation in large and medium size organizations', Journal of Manufacturing Technology Management, 24(5), pp. 688-710.

Bocken, N.M.P., Rana, P. and Short, S.W. (2015) 'Value mapping for sustainable business thinking', Journal of Industrial and Production Engineering, 32(1), pp. 67-81. doi:10.1080/21681015.2014.1000399.

Camila Romero, M., Villalobos, J. and Sanchez, M. (2015) 'Simulating the Business Model Canvas Using System Dynamics’, IEEE, pp. 527-534. doi: 978-1-46739464-2/15.

Carvalho, H., Duarte, S. and Cruz Machado, V. (2011) 'Lean, agile, resilient and green: divergencies and synergies', International Journal of Lean Six Sigma, 2(2), pp.151-179

Cudney, E. and Elrod, C. (2011) 'A comparative analysis of integrating lean concepts into supply chain management in manufacturing and service industries', International Journal of Lean Six Sigma, 2(1), pp. 5-22.

Deif, A. M. and ElMaraghy, H. (2014) 'Cost performance dynamics in lean production leveling', Journal of Manufacturing Systems, 33, pp. 613-623.

do Rosário Cabrita, M., Duarte, S., Carvalho, H. and Cruz-Machado, V. (2016) 'Integration of Lean, Agile, Resilient and Green Paradigms in a Business Model Perspective: Theoretical Foundations' IFAC-Papers On Line, 49(12), pp.13061311. 
Done, A., Voss, C. and G. Rytterc, N. (2011) 'Best practice interventions: Short-term impact and long-term outcomes', Journal of Operations Management, 29, pp. 500-513.

Duarte, S. and Cruz-Machado, V. (2013) 'Modelling lean and green: a review from business models', International Journal of Lean Six Sigma, 4(3), pp. 228-250.

Elias, A.A. (2016) 'Analysing the stakes of stakeholders in research and development project management: a systems approach', R\&D Management, 46(4), pp. 749760.

Filho, M. G. and Barco, C. F. (2015) 'A framework for choosing among different leanbased improvement programs', International Journal of Advanced Manufacturing Technology, 81, pp. 183-197. doi: 10.1007/s00170-015-7181-4.

Forrester, J. W. (2007a) 'System dynamics - a personal view of the first fifty years', System dynamics review, 23 (2), pp. 345-358. doi: 10.1002/sdr.382.

Forrester, J. W. (2007b) 'System dynamics - the next fifty years', System dynamics review, 23, pp. 359-370. doi: 10.1002/sdr.381.

Forrester, J.W. and Senge, P. (1980) 'Tests for building confidence in System Dynamics Models', TIMS Studies in the Management Sciences, 14, pp. 209-228.

Frazzon, E., Tortorella, G.L., Dávalos, R., Holtz, T. and Coelho, L. (2017) 'Simulationbased analysis of a supplier-manufacturer relationship in lean supply chains' International Journal of Lean Six Sigma, 8(3), pp.262-274.

Groesser, S. N. and Jovy, N. (2015) 'Business model analysis using computational modeling: a strategy tool for exploration and decision-making', Journal of Management Control, 27, pp. 61-88. doi: 1 0.1007/s00187-015-0222-1.

Gupta, V., Narayanamurthy, G., and Acharya, P. (2018) 'Can lean lead to green? Assessment of radial tyre manufacturing processes using system dynamics modelling', Computers \& Operations Research, 89, pp. 284-306.

Hallam, C., Flannery, W. and Liu, S.C. (2009) 'Lean production for technology management: Increasing production, reducing waste and quality improvement strategies in a plastic bags manufacturing facility', In International Conference on Management of Engineering \& Technology, Portland, August, pp. 11541162.

Jain, A., Bhatti, R. and Singh, H. (2014) 'Total productive maintenance (TPM) implementation practice: A literature review and directions', International Journal of Lean Six Sigma, 5(3), pp.293-323.

Jirasukprasert, P., Arturo Garza-Reyes, J., Kumar, V. and K. Lim, M. (2014) 'A Six Sigma and DMAIC application for the reduction of defects in a rubber gloves manufacturing process', International Journal of Lean Six Sigma, 5(1), pp. 2-21.

Kristensen, K., Kanji, G.K. and Dahlgaard, J.J. (1992) 'On measurement of customer satisfaction', Total Quality Management, 3 (2), pp. 123-128.

LAI (2012). 'LAI Enterprise Self-Assessment Tool (LESAT) V. 2', Retrieved 15/2/2016, from https://dspace.mit.edu/bitstream/handle/1721.1/84688/PRD_LESAT_2_Tool.pdf ?sequence $=1$.

Martis, M. S. (2006) 'Validation of Simulation Based Models: A Theoretical Outlook', The Electronic Journal of Business Research Methods, 4 (1), pp 39-46.

Narayanamurthy, G., and Gurumurthy, A (2016) 'Leanness assessment: a literature review', International Journal of Operations \& Production Management, 36(10), pp. 1115-1160.

Netland, T.H. and Ferdows, K. (2016) 'The S-Curve Effect of Lean Implementation' Production and Operations Management, 25(6), pp.1106-1120. 
Nightingale, D.J. and Mize, J.H. (2002) 'Development of a lean enterprise transformation maturity model', Information Knowledge Systems Management, 3(1), pp.15-30.

Oleghe, O. and Salonitis, K., 2015. 'Improving the efficacy of the lean index through the quantification of qualitative lean metrics', Procedia CIRP, 37, pp.42-47.

Oleghe, O. and Salonitis, K., 2016. 'Variation modeling of lean manufacturing performance using fuzzy logic based quantitative lean index', Procedia CIRP, 41, pp. 608-613

Oleghe, O. and Salonitis, K. (2018) 'Leanness Assessment Tools and Frameworks', In Progress in Lean Manufacturing (pp. 1-37). Springer, Cham.

Omogbai, O. and Salonitis, K. (2016) 'A lean assessment tool based on systems dynamics', in 26th CIRP Design Conference. 2016. Elsevier B.V.

Omogbai, O. and Salonitis, K. (2017) 'The implementation of 5S lean tool using system dynamics approach', Procedia CIRP, 60, pp. 380-385.

Osterwalder, A. and Pigneur, Y. (2010) 'Business Model Generation: A Handbook for Visionaries', Game Changers, and Challengers, Wiley, Hoboken, NJ.

Pavnaskar, S. J., Gershenson, J. K. and Jambekar, A. B. (2003) 'Classification scheme for lean manufacturing tools', International Journal of Production Research, 41(13), pp. 3075-3090. doi: 10.1080/0020754021000049817.

Pellow, B., Sorce, P., Frey, F., Oslon, L., Moore, K., \& Kirpichenko, S. (2003). 'The advertising agency's role in marketing communications demand creation', Center at Rochester Institute of Technology, No. PICRM-2003-05

Reiner, G. (2004) 'Customer-oriented improvement and evaluation of supply chain processes supported by simulation models', International Journal of Production Economics, 96, pp. 381-395. doi: 10.1016/j.ijpe.2004.07.004.

Rodrigues, L.L.R. and Dharmaraj, N. (2006) 'System dynamics approach for change management in new product development', Management Research News, 29(8), pp. 512-523.

Robinson, S., Radnor, Z.J., Burgess, N. and Worthington, C. (2012) 'SimLean: Utilising simulation in the implementation of lean in healthcare', European Journal of Operational Research, 219(1), pp.188-197.

Roth, N. and Franchetti, M. (2010) 'Process improvement for printing operations through the DMAIC Lean Six Sigma approach: a case study from Northwest Ohio, USA', International Journal of Lean Six Sigma, 1(2), pp. 119-133.

Shah, R. and Ward, P.T. (2003) 'Lean manufacturing: context, practice bundles, and performance', Journal of operations management, 21(2), pp.129-149.

Sterman, J. D. (2000) 'Business dynamics: Systems thinking and modeling for a complex world', Boston, MA: McGraw-Hill.

Stone, K.B. (2012) 'Four decades of lean: a systematic literature review', International Journal of Lean Six Sigma. Sigma, 3(2), pp.112-132.

Thun, J.H. (2004) Modelling Modern Maintenance-A System Dynamics Model Analyzing the Dynamic Implications of Implementing Total Productive Maintenance. In 22nd International System Dynamics Conference, Oxford, UK.

Uribe, J. (2008) 'Print Productivity: a system dynamics approach. A Research Monograph of the Printing Industry', Center at Rochester Institute of Technology, No. PICRM-2008-05.

Zott, C., Amit, R. and Massa, L. (2011) 'The Business Model: Recent Developments and Future Research', Journal of Management, 37(4), pp. 1019-1042. doi: $10.1177 / 0149206311406265$. 
Zott, C. and Amit, R. (2013) 'The business model: A theoretically anchored robust construct for strategic analysis', Journal of Management, 11(4), pp. 403-411. doi: $10.1177 / 1476127013510466$.

Zhang, T. and Li, Z. (2008) 'A Case Study based on the Dynamic Balanced Scorecard in Manufacturing Industry', IEEE.

Appendix 1. Description and values of model parameters

Appendix 2. List of equations 


\begin{tabular}{|c|c|c|c|c|c|}
\hline \multirow[t]{2}{*}{$\begin{array}{l}\text { Network of } \\
\text { suppliers and } \\
\text { partners that } \\
\text { make the } \\
\text { business model } \\
\text { work }\end{array}$} & $\begin{array}{l}\quad \text { Key } \\
\text { activities } \\
\text { Most important } \\
\text { things a } \\
\text { company must } \\
\text { do to make its } \\
\text { business model } \\
\text { work }\end{array}$ & \multicolumn{2}{|c|}{$\begin{array}{l}\quad \text { Value } \\
\text { proposition } \\
\text { Bundle of } \\
\text { products and } \\
\text { services that } \\
\text { create value for a } \\
\text { specific } \\
\text { customer } \\
\text { segment }\end{array}$} & $\begin{array}{l}\text { Customer } \\
\text { relationship } \\
\text { Types of } \\
\text { relationships a } \\
\text { company } \\
\text { establishes with } \\
\text { specific customer } \\
\text { segments }\end{array}$ & \multirow[t]{2}{*}{$\begin{array}{l}\text { Different groups } \\
\text { of people or } \\
\text { organizations an } \\
\text { enterprise aims } \\
\text { to reach and } \\
\text { serve }\end{array}$} \\
\hline & $\begin{array}{l}\quad \text { Key } \\
\text { resources } \\
\text { Most important } \\
\text { assets required } \\
\text { to make a } \\
\text { business model } \\
\text { work }\end{array}$ & & & $\begin{array}{l}\quad \text { Channels } \\
\text { How a company } \\
\text { communicates } \\
\text { with and reaches } \\
\text { its customer } \\
\text { segments to } \\
\text { deliver a value } \\
\text { proposition }\end{array}$ & \\
\hline \multicolumn{3}{|c|}{$\begin{array}{l}\text { Cost } \\
\text { structure } \\
\text { All costs incurred to operate a business } \\
\text { model }\end{array}$} & \multicolumn{3}{|c|}{$\begin{array}{l}\text { Revenue } \\
\text { streams }\end{array}$} \\
\hline
\end{tabular}

Figure 1. The Business Model Canvas (Osterwalder and Pigneur, 2010)

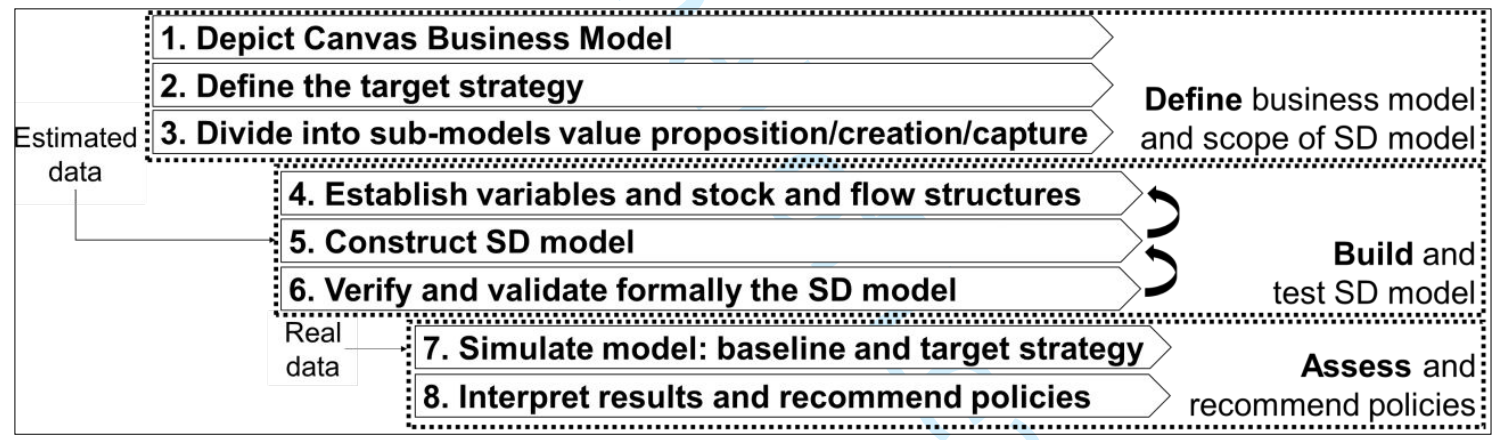

Figure 2. The proposed modelling methodology

(a)

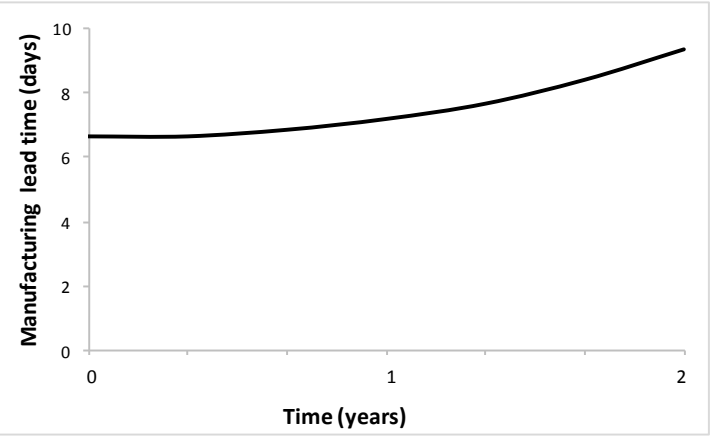

(b)

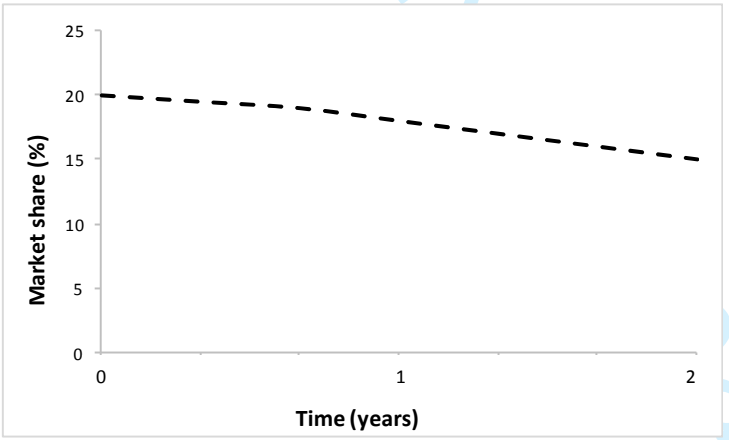

Figure 3. Reference mode showing pattern of a) manufacturing lead time and b) market share, if status quo is maintained 


\begin{tabular}{|c|c|c|c|c|}
\hline \begin{tabular}{l|} 
KEY PARTNERS \\
-Local suppliers (60\%) \\
-Overseas suppliers \\
$(40 \%)$
\end{tabular} & $\begin{array}{l}\text { KEY ACTIVITIES } \\
\text {-Printing } \\
\text {-Scheduling } \\
\text {-Handling and tracking } \\
\text { orders } \\
\text {-Maintaining customers } \\
\text {-Dispatching } \\
\text { KEY RESOURCES } \\
\text {-Multifunctional workforce } \\
\text {-Sales Agents } \\
\text {-Machinery } \\
\text {-IT system }\end{array}$ & \begin{tabular}{|l|} 
VALUE PROPOSITION \\
Manufacturing of printed \\
labels and wrapping \\
solutions: \\
- Quick turnarounds \\
- High Quality products \\
- Timely order information
\end{tabular} & \begin{tabular}{|l|} 
CUSTOMER RELATIONSHIPS \\
-Handling orders \\
Placing, tracking, dispathing \\
-Design and advise of packaging \\
solutions \\
CHANNELS \\
-Sales Agents (75\%) \\
Communication with 3rd party \\
customers \\
-Direct Customer Communication \\
$(25 \%)$
\end{tabular} & $\begin{array}{l}\text { CUSTOMER SEGMENTS } \\
\text {-Small and mid-sized } \\
\text { industrial packagers } \\
\text {-Regular frequency, size } \\
\text { and type of orders }\end{array}$ \\
\hline $\begin{array}{l}\text { COST STRUCTURE } \\
\text {-Raw materials } \\
\text {-IT infrastructure } \\
\text {-Overheads } \\
\text {-Salaries }\end{array}$ & $\begin{array}{l}\text {-Machinery Set-ups } \\
\text {-Logistics } \\
\text {-Training } \\
\text {-Plant Maintenance }\end{array}$ & & \multicolumn{2}{|c|}{$\begin{array}{l}\text { REVENUE STREAMS: } \\
\text {-Printed packaging sales } \\
\text { Discounts for agents, and larger and frequent orders } \\
\text {-Dispatching service }\end{array}$} \\
\hline
\end{tabular}

Figure 4. Business Model Canvas of the Case Company

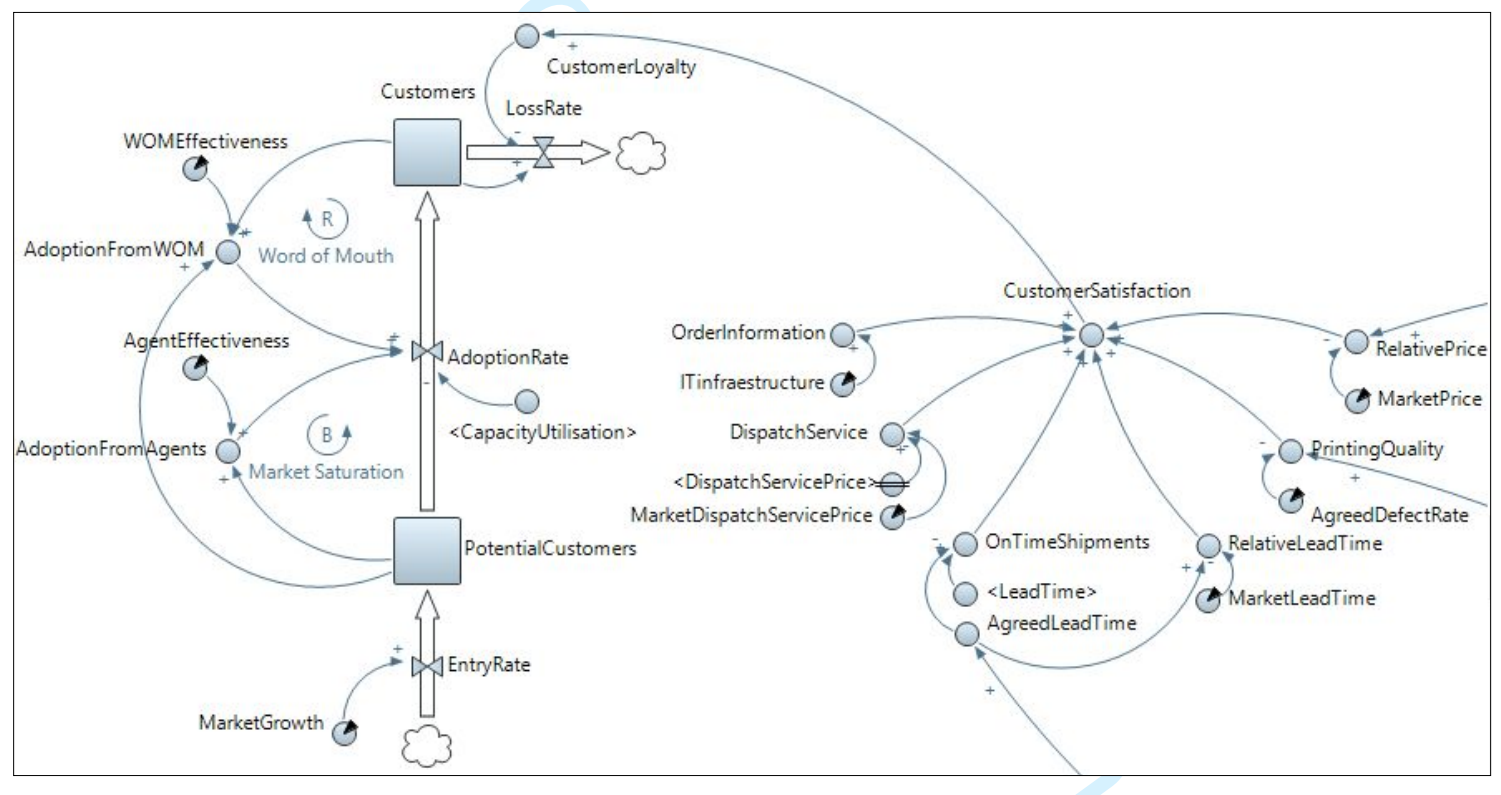

Figure 5. Value proposition sub-model for the case company 


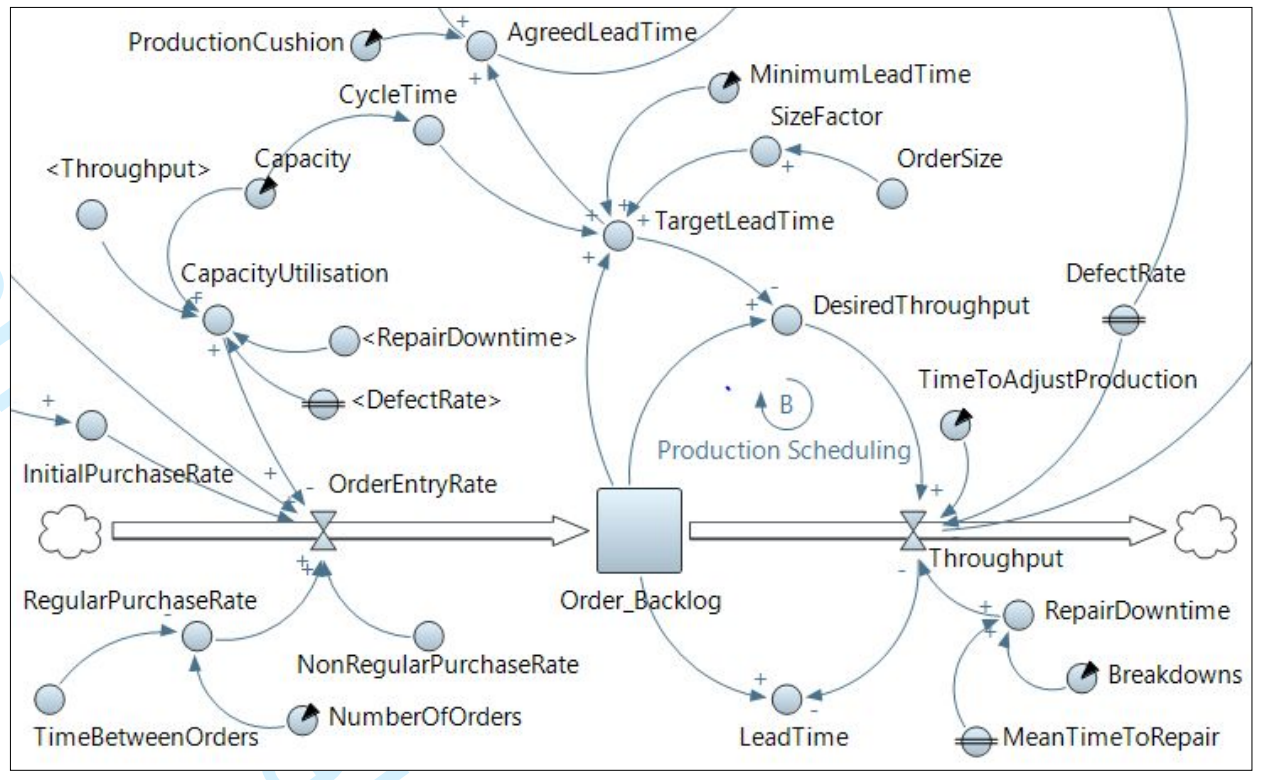

Figure 6. Value creation sub-model for the case company

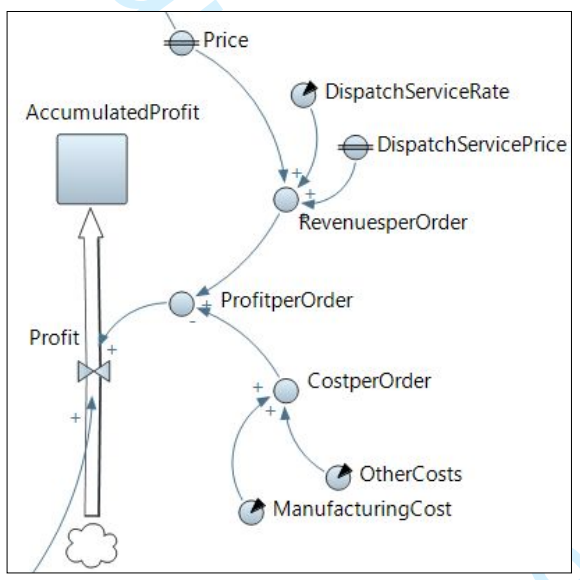

Figure 7. Value capture sub-model for the case company 


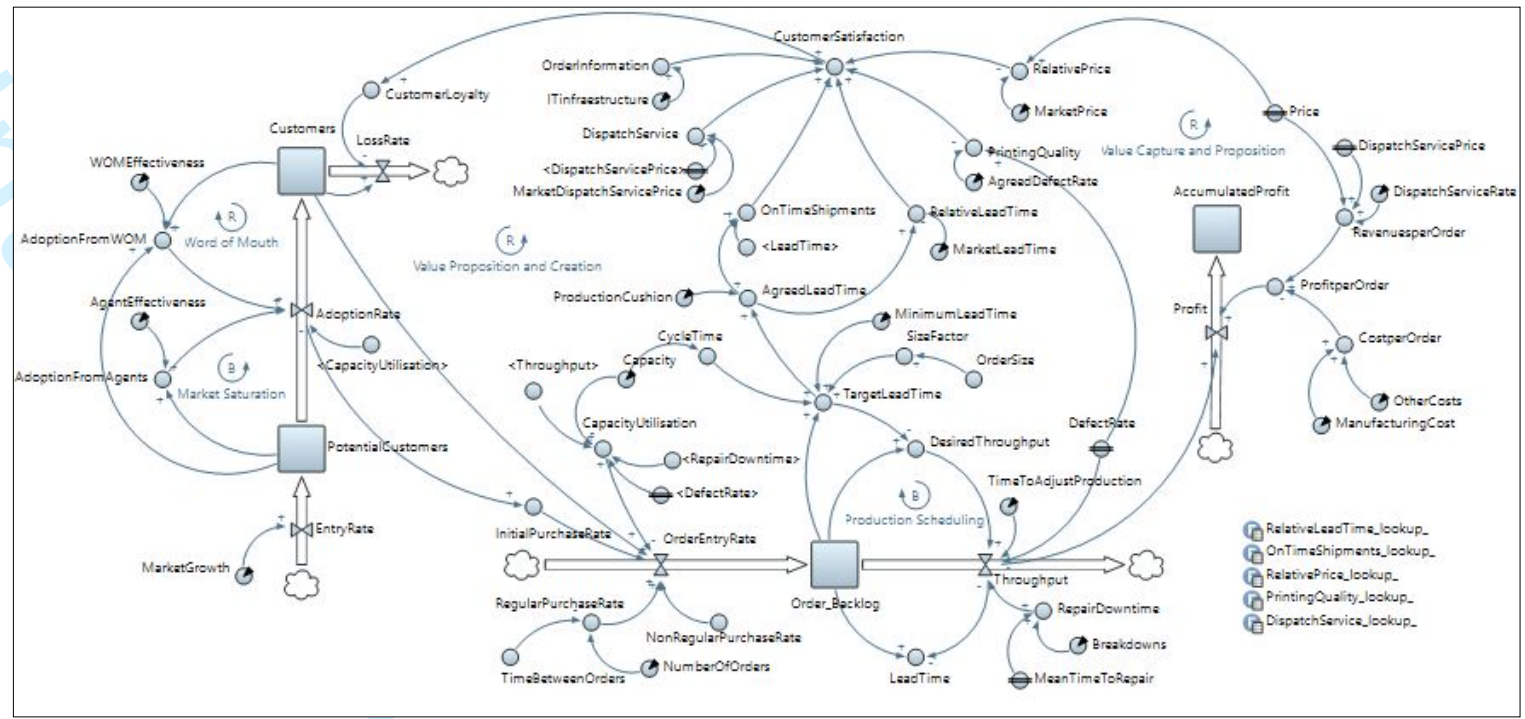

Figure 8. System dynamics model of the case study company depicting its business model

\begin{tabular}{l} 
PelativeLeadTime_lookup_- Table Function \\
\hline \begin{tabular}{|l|l|}
\hline Argument & Value \\
\hline 0 & 100 \\
0.2 & 75 \\
0.4 & 62.5 \\
0.6 & 56.25 \\
0.8 & 53.125 \\
1 & 50 \\
1.2 & 46.875 \\
1.4 & 43.75 \\
1.6 & 37.5 \\
1.8 & 25 \\
\hline
\end{tabular}
\end{tabular}

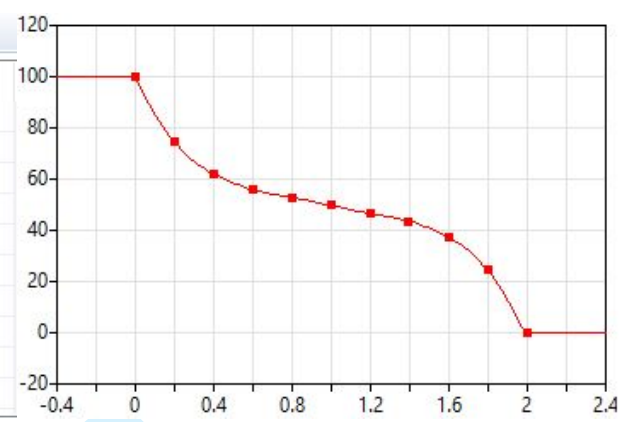

Figure 9. Table Function depicting the relationship between customer satisfaction and relative lead time 

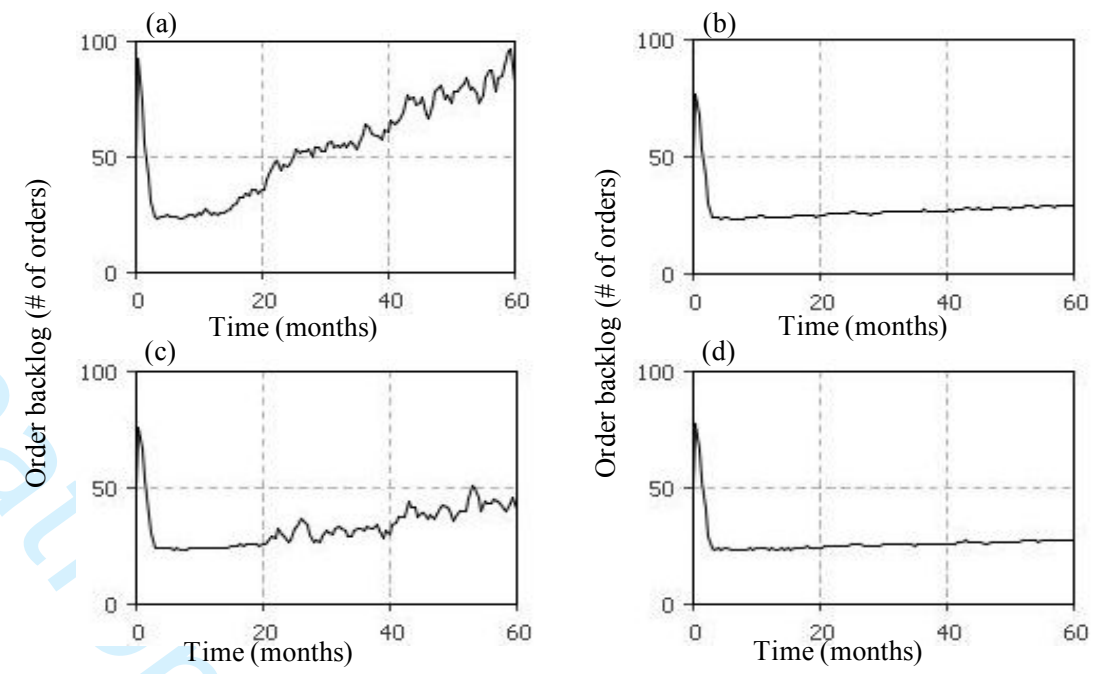

Figure 10. 5-year trend depicting the order backlog: (a) current baseline; (b) scenario 2.1; (c) scenario 2.2 ; (d) scenario 2.3
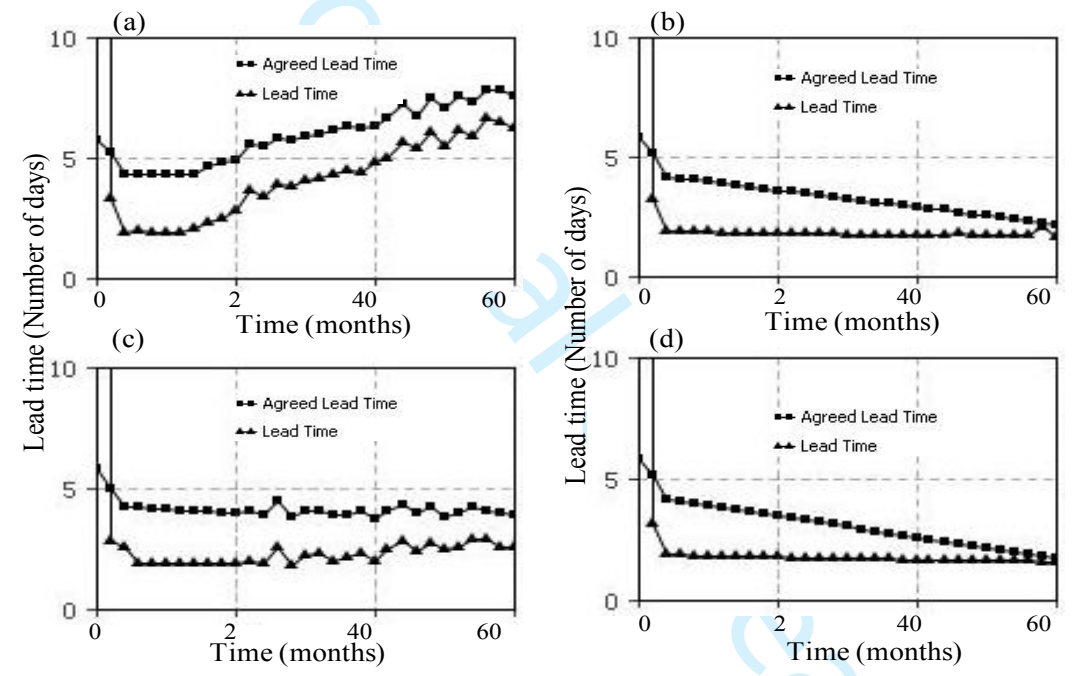

Figure 11. 5-year trend depicting the lead time: (a) current baseline; (b) scenario 2.1; (c) scenario 2.2; (d) scenario 2.3 
(a)

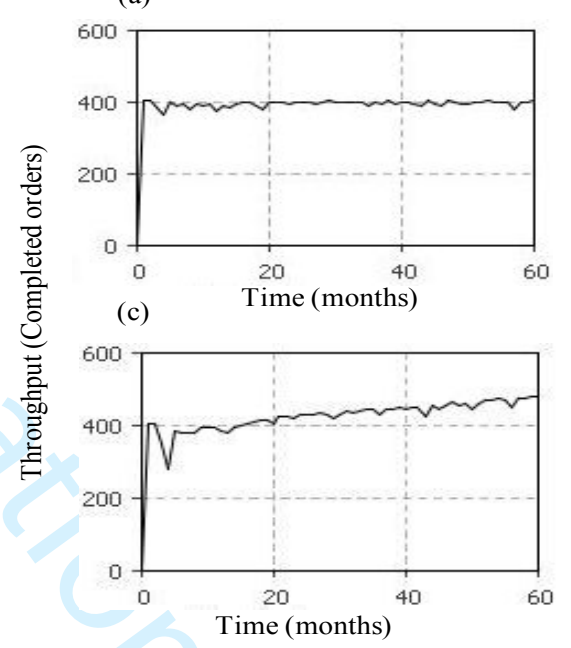

(b)

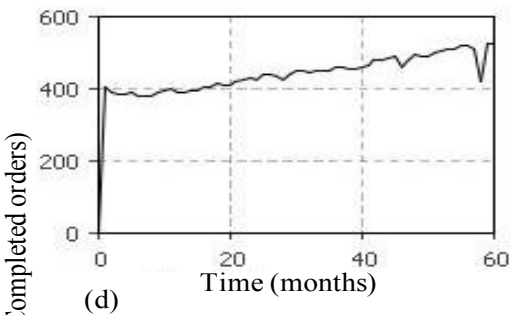

(d)

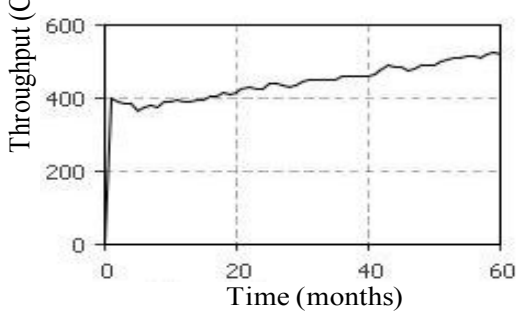

Figure 12. 5-year trend depicting throughput: (a) current baseline; (b) scenario 2.1; (c) scenario 2.2; (d) scenario 2.3

(a)

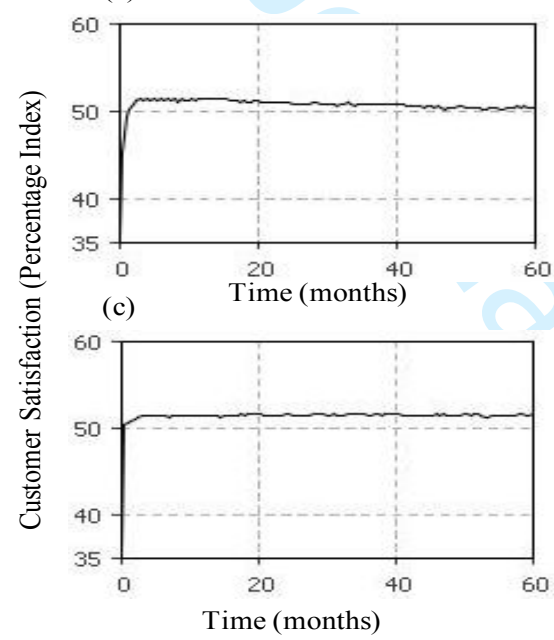

(b)

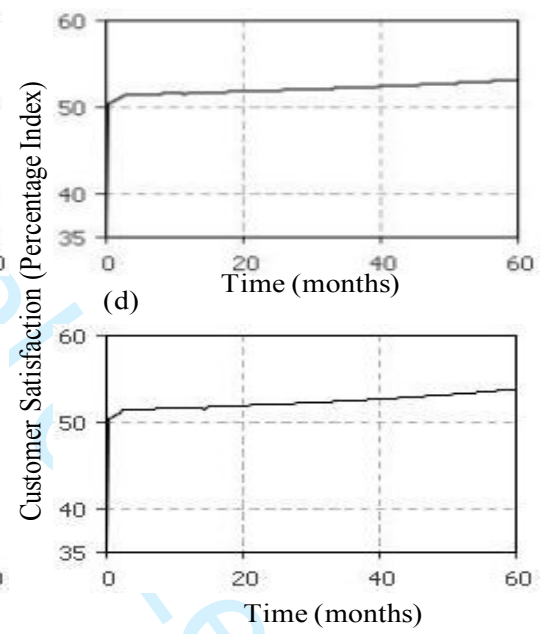

Figure 13. 5-year trend depicting customer satisfaction index: (a) current baseline; (b) scenario 2.1; (c) scenario 2.2 ; (d) scenario 2.3 
(a)

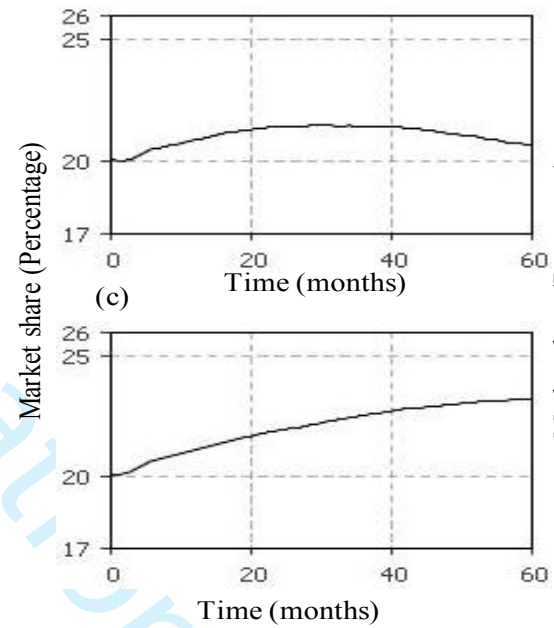

(b)

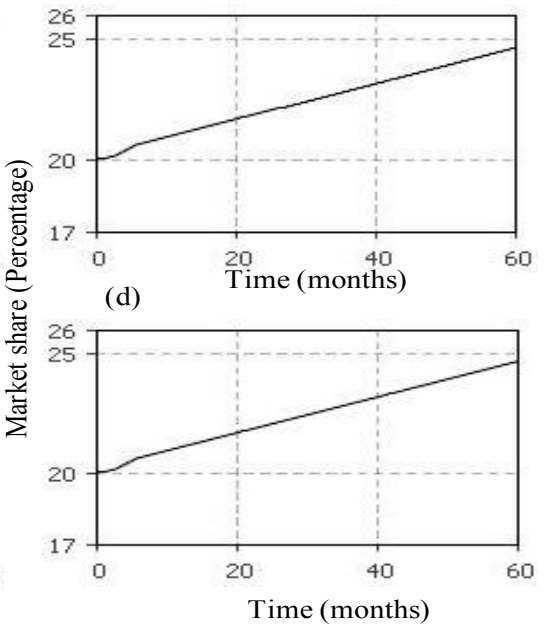

Figure 14. 5-year trend depicting market share: (a) current baseline; (b) scenario 2.1; (c) scenario 2.2; (d) scenario 2.3 


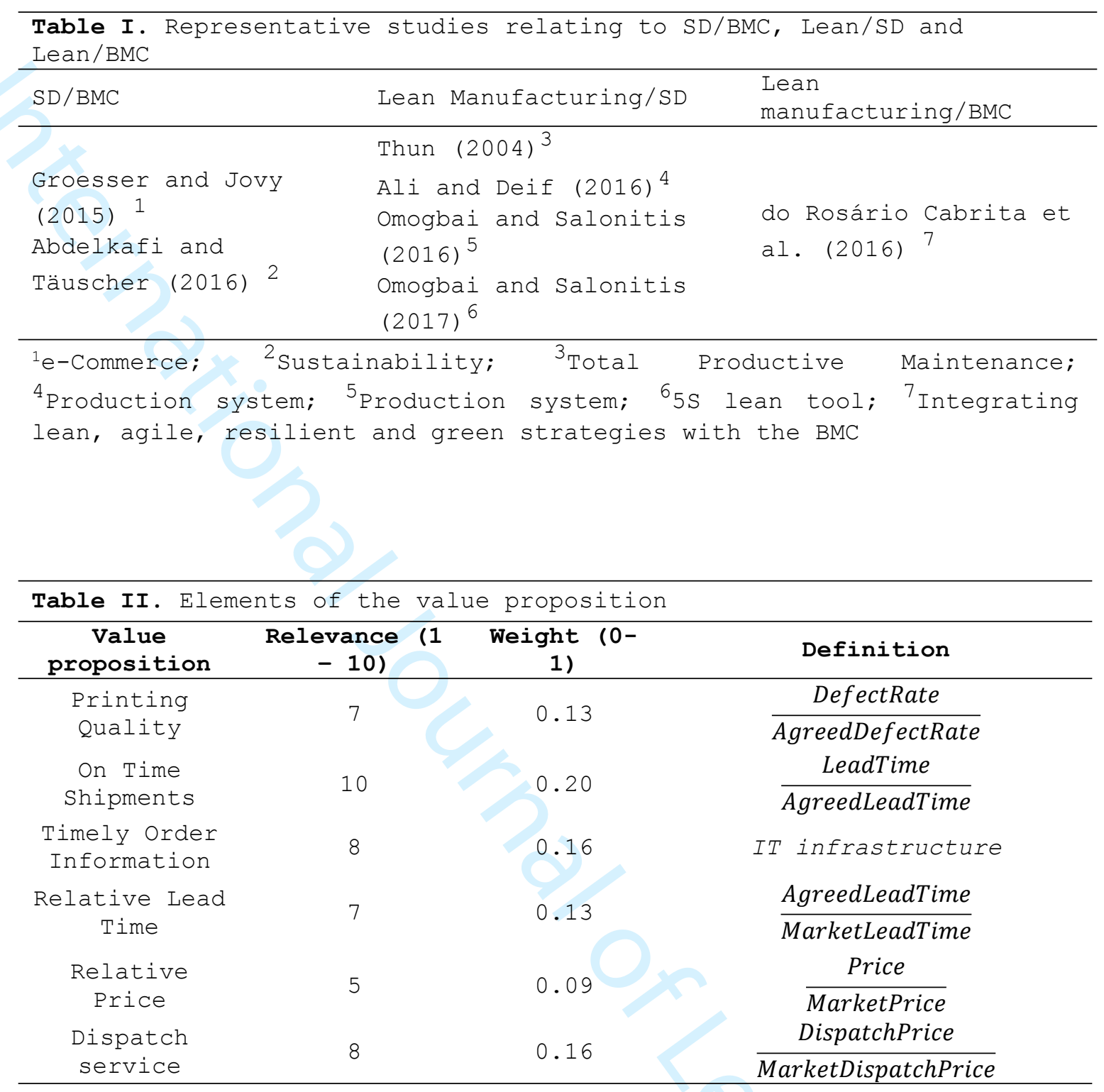

\begin{tabular}{|c|c|c|}
\hline Scenarios & $\begin{array}{l}\text { Description of the } \\
\text { strategy }\end{array}$ & Adjusted parameters \\
\hline 1. Current baseline & $\begin{array}{l}\text { The business status quo } \\
\text { is maintained over time. }\end{array}$ & None \\
\hline $\begin{array}{l}\text { 2. Implementation of } \\
\text { lean manufacturing } \\
\text { practices }\end{array}$ & $\begin{array}{l}\text { A number of lean } \\
\text { manufacturing } \\
\text { improvements are } \\
\text { simultaneously applied } \\
\text { to the production } \\
\text { process }\end{array}$ & $\begin{array}{l}\text { Breakdowns } \\
\text { Defect rate } \\
\text { Production cushion } \\
\text { Time to adjust } \\
\text { production } \\
\text { Cycle time }\end{array}$ \\
\hline
\end{tabular}


3 Optimisation of

lead time

\author{
An optimisation \\ experiment is executed \\ to determine what \\ production enhancements \\ would minimise lead \\ time.
}

Breakdowns

Defect rate

Production cushion

Time to adjust

production

cycle time

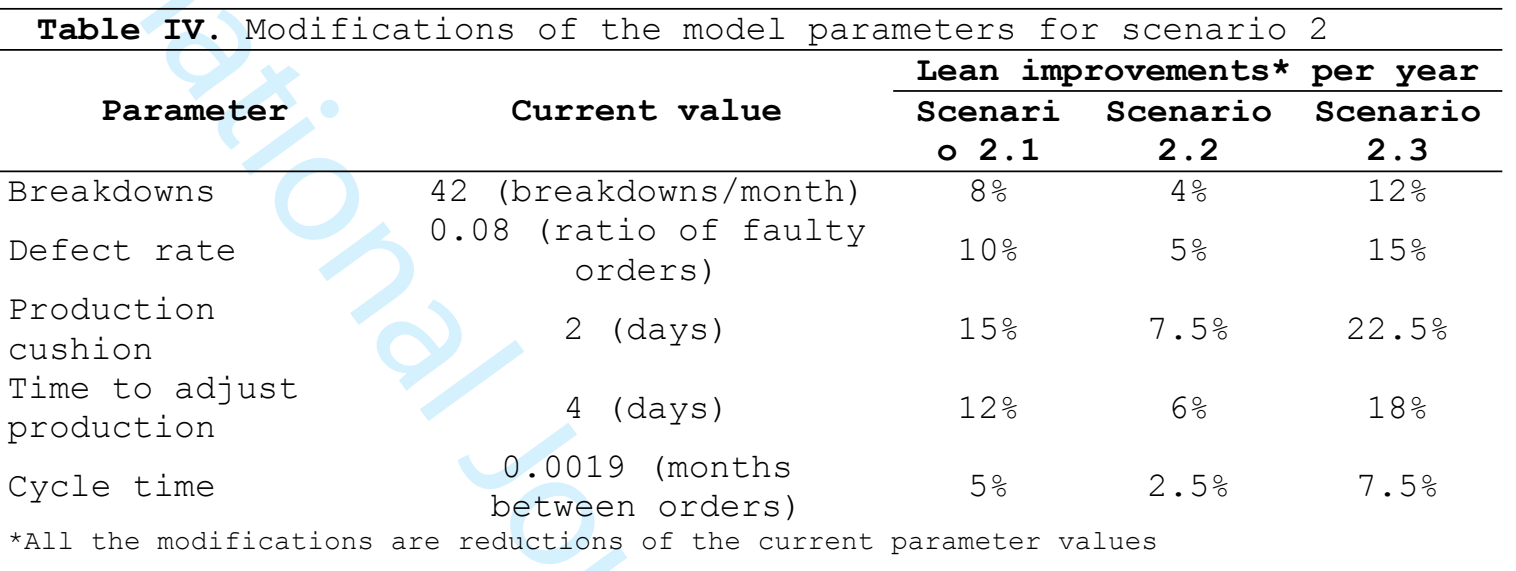

Table V. Parameter ranges for the optimisation scenario

\begin{tabular}{lcccc}
\hline Parameter & Type & $\begin{array}{c}\text { Current } \\
\text { value }\end{array}$ & $\begin{array}{c}\text { Minimum } \\
\text { value }\end{array}$ & $\begin{array}{c}\text { Maximum } \\
\text { value }\end{array}$ \\
\hline Breakdowns & $\begin{array}{c}\text { Continuo } \\
\text { us } \\
\text { Continuo } \\
\text { us }\end{array}$ & 42 & 38 & 46 \\
Production cushion & $\begin{array}{c}\text { Continuo } \\
\text { us }\end{array}$ & 0.095 & 0.072 & 0.088 \\
$\begin{array}{l}\text { Time to adjust } \\
\text { production } \\
\text { Capacity* }\end{array}$ & $\begin{array}{c}\text { Continuo } \\
\text { us }\end{array}$ & 0.224 & 0.197 & 0.109 \\
Continuo & us & 525 & 499 & 551
\end{tabular}

*Due to decimal figure limitations of the AnyLogic software, the cycle time parameter $(0.001904)$ was adapted into a capacity parameter as follows: $1 / 0.001904=525$. The model results are not affected by this adjustment.

\begin{tabular}{lc}
\hline $\begin{array}{c}\text { Table VI. Parameter values for the optimum lead } \\
\text { time }\end{array}$ & Values for optimum lead \\
Parameter & 38 \\
\hline Breakdowns & 0.076 \\
Defect rate & 0.083 \\
Production cushion & 0.211 \\
Time to adjust & \\
production & 551 \\
Capacity & \\
\hline
\end{tabular}


Appendix 1. Description and values of model parameters

\begin{tabular}{|c|c|c|}
\hline SD Parameter & Interpretation in real business & Value (units) \\
\hline Agent Effectiveness & $\begin{array}{l}\text { Constant fraction of potential adopter population that } \\
\text { place an order as a result of the advertising of the sales } \\
\text { agents }\end{array}$ & $0.0015(\mathrm{n} / \mathrm{a})$ \\
\hline Agreed Defect Rate & Contractual rate of defects agreed with the customer & $0.01(\mathrm{n} / \mathrm{a})$ \\
\hline Breakdowns & Average number of breakdowns per month & 42 (breakdowns) \\
\hline Cycle Time & $\begin{array}{l}\text { Time between the completion of job orders (equivalent } \\
\text { to Takt Time) }\end{array}$ & 0.0019047 (months) \\
\hline Defect Rate & Rate of faulty orders & $0.08(\mathrm{n} / \mathrm{a})$ \\
\hline Dispatch Service Rate & $\begin{array}{l}\text { Fraction of orders that are shipped through the } \\
\text { dispatching service }\end{array}$ & $0.10(\mathrm{n} / \mathrm{a})$ \\
\hline Dispatch Service Price & $\begin{array}{l}\text { Surcharge applied to the order price for the dispatch } \\
\text { service }\end{array}$ & $0.04(\mathrm{n} / \mathrm{a})$ \\
\hline IT Infrastru & $\begin{array}{l}\text { Considers whether there is IT infrastructure in place to } \\
\text { report the state of the orders to customers or not }\end{array}$ & 0 (binary) \\
\hline Manufacturing Cost & Cost of producing one standard order & $£ 22$ \\
\hline $\begin{array}{l}\text { Market Dispatch } \\
\text { Service Price }\end{array}$ & $\begin{array}{l}\text { Average surcharge in the market applied to the order } \\
\text { prices for dispatch services }\end{array}$ & $0.03(\mathrm{n} / \mathrm{a})$ \\
\hline Market Growth & $\begin{array}{l}\text { Growth of the market in terms of number of new } \\
\text { potential customers per month }\end{array}$ & 25 (customers) \\
\hline Market Lead Time & Average time to produce a standard order in the market & 0.2381 (months) \\
\hline Market Price & Average price of one standard order in the market & $£ 160$ \\
\hline Mean Time to Repair & Time spent in repairing broken down machines & 0.00397 (months) \\
\hline Minimum Lead Time & $\begin{array}{l}\text { Time to produce a standard order when the production } \\
\text { line is idle }\end{array}$ & 0.04762 (months) \\
\hline Number of Orders & $\begin{array}{l}\text { Average number of different job orders that a customer } \\
\text { places with every order }\end{array}$ & 1.8 (orders) \\
\hline $\begin{array}{l}\text { Non Regular Purchase } \\
\text { Rate }\end{array}$ & Rate at which non-regular customers place job orders & 0.0833 (orders) \\
\hline Other Costs & $\begin{array}{l}\text { Associated costs of manufacturing one standard order } \\
\text { such as overheads and salaries }\end{array}$ & $£ 7$ \\
\hline Price & Price of one standard order & $£ 160$ \\
\hline Production Cushion & $\begin{array}{l}\text { Safety time cushion added to the target lead time that is } \\
\text { offered to customers }\end{array}$ & 0.09524 (months) \\
\hline $\begin{array}{l}\text { Time to Adjust } \\
\text { Production }\end{array}$ & $\begin{array}{l}\text { Required time period to adjust the production to } \\
\text { demand changes }\end{array}$ & 0.2 (months) \\
\hline WOM Effectiveness & $\begin{array}{l}\text { Rate of contacts per person per month within the } \\
\text { market that induce a potential customer to place an } \\
\text { order }\end{array}$ & $0.0030(\mathrm{n} / \mathrm{a})$ \\
\hline
\end{tabular}

Appendix 2. List of equations 
1. AdoptionRate $=$ CapacityUtilisation $<99$ ? $($ AdoptionFromAgents + AdoptionFromWOM): 01 .

2. AdoptionFromAgents $=$ PotentialCustomers $*$ AgentEffectiveness

3. AdoptionFromWOM $=$ WOMEffectiveness $*$ PotentialCustomers $*$ Customers/ (PotentialCustomers + Customers)

4. $\quad$ LossRate $=\operatorname{delay}(\max (\text { Customers } *(1-\text { CustomerLoyalty }) / 100,0), 6)^{2}$.

5. EntryRate $=$ MarketGrowth

6. RelativeLeadTime $=$ AgreedLeadTime $/$ MarketLeadTime

7. PrintingQuality $=$ DefectRate/AgreedDefectRate

8. OnTimeShipments $=$ LeadTime/AgreedLeadTime

9. OrderInformation $=$ ITinfraestructure

10. RelativeLeadTime $=$ AgreedLeadTime $/$ MarketLeadTime

11. RelativePrice $=$ Price MarketPrice

12. RelativeDispatchService $=$ DispatchPrice $/$ MarketDispatchPrice

13.

CustomerSatisfaction $=$ OrderInformation $* 0.18+$ RelativeLeadTime_lookup_.get(RelativeLeadTime) $*$ $0.16+$ OnTimeShipments_lookup_.get(OnTimeShipments ) $* 0.22+$

RelativePrice_lookup_get(RelativePrice) $* 0.11+$ PrintingQuality_lookup_.get(PrintingQuality) $* 0.15+$ DispatchService_lookup_.get(DispatchService) $* 0.18$

14. CustomerLoyalty $=0.75+0.58 *($ CustomerSatisfaction $/ 100-0.67)$

15. OrderEntryRate $=$ CapacityUtilisation $<99$ ? $\operatorname{smooth}(($ RegularPurchaseRate $*$ Customers $* 0.175+$

NonRegularPurchaseRate * Customers * 0.825 + InitialPurchaseRate),1): RegularPurchaseRate *

Customers $* 0.175^{2}$.

16. RegularPurchaseRate $=(1 /$ TimeBetweenOrders $)$

17. TimeBetweenOrders $=$ lognormal $(0.0814,0.958,0.238)$

18. InitialPurchaseRate $=$ AdoptionRate

19. TargetLeadTime $=\max ($ MinimumLeadTime, CycleTime $*$ (OrderBacklog + SizeFactor $)$

20. AgreedLeadTime $=$ TargetLeadTime + ProductionCushion

21. SizeFactor $=$ OrderSize $/ 89.75$

22. DesiredThroughput $=$ OrderBacklog/TargetLeadTime

23. Throughput $=$

$\max ($ delay(DesiredThroughput $*(1-$ DefectRate $) *(1-$ RepairDowntime $)$, TimeToAdjustProduction $), 0){ }^{1}$.

24. RepairDowntime $=$ Breakdowns $*$ MeanTimeToRepair

25. Capacity $=1 /$ CycleTime

26. CapacityUtilisation $=100 *(($ Throughput $/((1-$ DefectRate $) *(1-$ RepairDowntime $))) /$ Capacity $)$

27. Profit $=$ Throughput $*$ ProfitPerOrder

28. RevenuesPerOrder $=$ Price + DispatchServicePrice $*$ DispatchServiceRate

29. CostPerOrder $=$ ManufacturingCost + OtherCosts

39. ProfitPerOrder $=$ RevenuesPerOrder + CostPerOrder

${ }^{1}$ The flows of Adoption Rate and Order Entry Rate include if-conditions for limiting the number of customers and incoming orders when the capacity utilisation reaches $99 \%$. The structure in AnyLogic of the if-statement is: '(Condition) ? (Value if condition is true) : (Value if condition is false)'.

${ }^{2}$ The flows of Loss Rate and Throughput were guaranteed to be positive using the structure of 'max(flow_value,0)'. 


\section{Analysis of lean manufacturing strategy using system dynamics modelling of a business model}

Gomez Segura, Miguel

Emerald

Gomez Segura M, Oleghe O \& Salonitis K. Analysis of lean manufacturing strategy using system dynamics modelling of a business model. International Journal of Lean Six Sigma, Available online 22 August 2019

https://doi.org/10.1108/lJLSS-05-2017-0042

Downloaded from Cranfield Library Services E-Repository 